\title{
Actividad conjunta y habla: una aproximación al estudio de los mecanismos de influencia educativa ${ }^{1}$
}

\author{
César Coll, Rosa Colomina, Javier Onrubia y \\ M. JosÉ ROCHERA \\ Universidad de Barcelona
}

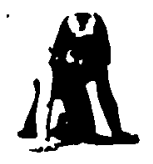

\section{Resumen}

El articulo presenta las principales opciones teóricas y metodológicas de un proyecto de investigación cuyo objetivo principal es el estudio de algunos mecanismos de influencia educativa que se manifiestan en, o actúan a través de, la interacción profesor/grupo de alumnos y adulto/niño. Utilizando como punto de partida el concepto de interactividad, término acuñado para designar las formas de organización de la actividad conjunta en torno al contenido o tarea que están llevando a cabo los participantes, se analizan dos mecanismos de influencia educativa: la cesión y el traspaso progresivos del control y la responsabilidad y la construcción progresiva de sistemas de significados compartidos.

Palabras clave: Actividad conjunta; Cesión del control y de la responsabilidad; Construcción conjunta de significados compartidos; Discurso educacional; Influencia educativa; Interacción adulto/niño; Interacción profesor/grupo de alumnos; Interactividad.

\section{Joint activity and speech: an approach to the study of educational influence devices}

\section{Abstract}

This paper presents the theoretical and methodological options of a research project whose main objective is the study of some mechanisms of educational influence. The stress is placed on the mechanisms involved in teacher/pupil's group interaction and adult/child interaction. Taking the concept of interactivity - the forms of organization of the participants joint activity on content or task - as a starting point, two mecbanisms of educational influence are analyzed: the progressive transfer of responsibility and control and the progressive construction of shared meanings.

Keywords: Adult/child interaction; Educational discourse; Educational influence; Interactivity; Joint activity; Joint construction of shared meanings; Teacherpupil's group interaction; Transfer of responsability and control. 


\section{INTRODUCCION}

El objetivo de este artículo es presentar las principales opciones teóricas y metodológicas de un proyecto de investigación en curso en el Departamento de Psicología Evolutiva y de la Educación de la Universidad de Barcelona. El núcleo de la problemática que nos ocupa puede definirse, en una primera aproximación, como el estudio de algunos mecanismos de influencia educativa que se manifiestan en, o actúan a través de, la interacción entre el profesor y los alumnos, en el caso de la educación escolar, y la interacción entre el adulto y el niño, en el caso de situaciones educativas no escolares.

En el transcurso del artículo se irá precisando qué entendemos por «mecanismos de influencia educativa» y también por «interacción». B̧aste señalar, por el momento, que al hablar de «mecanismos de influencia educativa" se quiere desplazar el acento desde los procesos de aprendizaje hacia los procesos de enseñanza. El objetivo que nos guía no es sólo comprender mejor cómo los alumnos aprenden unos determinados contenidos, sino también, y sobre todo, comprender mejor como unos alumnos concretos aprenden unos determinados contenidos gracias a la ayuda que reciben de su profesor, como consecuencia de la influencia educativa que ejerce sobre ellos. El énfasis, pues, no recae sobre los procesos de aprendizaje en sí mismos, en toda su generalidad y al margen del contexto en el que tienen lugar, sino sobre los procesos de aprendizaje que, de alguna manera, pueden ser interpretados como el resultado de un proceso de enseñanza.

En cierto modo, nuestro proyecto de investigación se sitúa en un espacio intermedio entre, por una parte, lo que han sido tradicionalmente las preocupaciones de una psicología interesada por los problemas educativos, guiada a menudo por la voluntad de llegar a prescribir formas más eficaces y más «científicas» de enseñar, y por otra, las preocupaciones de unas didácticas interesadas en dar apoyo o fundamentar «científicamente», mediante un recurso a la psicología, unas determinadas propuestas de enseñanza. Dejando al margen el complejo y polémico tema de las relaciones entre la psicología y las didácticas, cuyo tratamiento escapa a las posibilidades de este artículo, sí que conviene señalar, en cambio, que la pertinencia de la problemática apuntada hunde sus raíces en nuestro caso en una cierta manera de entender el papel de la Psicología de la Educación en el concierto de las disciplinas psicológicas y educativas, así como sus aportaciones a la elaboración de una teoría educativa y a la resolución de problemas educativos concretos (Coll, 1988); y también, como tendremos ocasión de comentar más adelante, en una cierta manera de entender cómo aprenden los alumnos y cómo se puede favorecer y potenciar el aprendizaje en la escuela: lo que hemos denominado, en algunas publicaciones anteriores, «la concepción constructivista de la enseñanza y del aprendizaje escolar» (Coll, 1987).

El énfasis sobre «los mecanismos de influencia educativa» supone pues una ampliación, o mejor quizás una reformulación, del campo de estudio habitual de la Psicología de la Educación. No se abandona en absoluto el interés por los procesos de aprendizaje de los alumnos y alumnas; más bien, lo que se pretende es ubicar su estudio en estrecha continuidad e interrelación con los procesos de enseñanza. El objetivo último no es, sin embargo, describir cómo enseñan los profesores o indagar por qué enseñan como enseñan, al estilo de buena parte de las investigaciones didácticas al uso. El objetivo último, en términos un poco más concretos que los que hemos utilizado hasta ahora, es identificar, describir e intentar comprender algunos de los mecanismos mediante los cuales una persona, que actúa como agente educativo -madre, profesor, igual-, consigue incidir sobre otra persona - hijo, alumno, igualayudándole a construir un sistema de significados - y, por lo tanto, a realizar una serie de aprendizajes - relativos a una determinada parcela de la realidad, es decir, a un contenido concreto.

El marco teórico de referencia que hemos ido delimitando progresivamente postula que algunos de los mecanismos de influencia educativa más importantes operan precisamente 
en el ámbito de las relaciones y de los intercambios interpersonales. Sin embargo, las relaciones interpersonales en el contexto educativo, las pautas interactivas entre los participantes, no son un objeto de estudio en sí mismas en nuestras investigaciones. Lo que nos interesa es más bien detectar los mecanismos de influencia educativa que $-\mathrm{y}$ se trata, por supuesto, de una hipótesis que habrá que confrontar con los datos empíricos - toman cuerpo en, y actúan a través de, las relaciones interpersonales que se establecen entre los participantes en el acto educativo. Por otra parte, aunque nuestro marco teórico postula que algunos mecanismos de influencia educativa - particularmente importantes y decisivos, por añadidura - se sitúan en el campo de lo interpersonal, estamos convencidos de que el análisis de la interacción no es el único análisis pertinente para una mejor comprensión de la práctica educativa. En otros términos, pensamos que hay determinados mecanismos de influencia educativa que no siempre ni necesariamente se manifiestan en el contacto interpersonal directo entre los participantes. El análisis de la interacción sería pues, en esta perspectiva, sólo uno de los aspectos a tener en cuenta en el intento de alcanzar una comprensión más amplia y sistemática de los mecanismos de influencia educativa y de la práctica educativa en general.

Hemos organizado la exposición en cuatro apartados. En el primero, se presentan, de manera muy breve y sintética, los principios teóricos y las ideas directrices del proyecto. En el segundo, se describen las características de algunas de las situaciones de observación utilizadas para la recogida de los datos. En el tercero, se exponen los tipos de análisis que estamos llevando a cabo. En el cuarto, por último, se subrayan algunas dificultades surgidas en el desarrollo del proyecto y se revisan críticamente las soluciones adoptadas.

\section{EL MARCO TEORICO DEL PROYECTO: PRINCIPIOS BASICOS E IDEAS DIRECTRICES}

La delimitación de la problemática, las preguntas concretas que tratan de responder las investigaciones, la planificación de las situaciones de observación, la selección de los datos finalmente registrados y los procedimientos de análisis establecidos para los mismos se apoyan en un conjunto de ideas directrices y principios básicos, que configuran el marco teórico del proyecto. En lo que sigue, enunciaremos de manera esquemática estos principios, subrayando brevemente sus principales implicaciones teóricas y metodológicas ${ }^{2}$.

(i) El primero de estos principios señala que, en general, no parece posible llegar a identificar lo que aprenden o no los alumnos en una situación de aula analizando únicamente sus actuaciones individuales. Más bien, el análisis debe centrarse en la interactividad profesor/alumnos, expresión acuñada para designar la articulación de las actividades del profesor y de los alumnos en torno a un contenido o a una tarea de aprendizaje. La idea básica que subyace al concepto de interactividad es, pues, que resulta imposible entender lo que hacen ${ }^{3}$ los alumnos, cómo y por qué lo hacen y qué aprendizajes llevan a cabo haciendo lo que hacen, si no tenemos en cuenta simultáneamente lo que hace el profesor, cómo y por qué lo hace; e inversamente, no podemos entender lo que hace un profesor, cómo lo hace y por qué lo hace, si no tenemos en cuenta simultáneamente lo que hacen los alumnos, cómo lo hacen y por qué lo hacen. El concepto de interactividad, definida como la articulación de las actuaciones del profesor y de los alumnos (o del adulto y del niño, en el caso de situaciones educativas no escolares) en torno a una tarea o un contenido de aprendizaje determinado, supone pues una llamada de atención sobre la importancia de analizar las actuaciones de los alumnos en estrecha vinculación con las actuaciones del profesor; y recíprocamente.

El concepto de interactividad es más amplio que el concepto de interacción, puesto que incluye no sólo los intercambios comunicativos directos entre los diferentes participantes en una actividad conjunta, sino también otras actuaciones que son en apariencia de naturaleza esencialmente individual (por ejemplo, en el contexto escolar, la realización 
individual por los alumnos de ejercicios de papel y lápiz, la corrección de los mismos por el profesor en ausencia de los alumnos, etc.) pero cuya significación educativa es inseparable del marco más amplio de la actividad conjunta. En este sentido, podemos decir que la interactividad profesor/alumnos, entendida como las formas de organización de la actividad conjunta, define el marco en el que cobran sentido, desde el punto de vista de la influencia educativa, las actuaciones respectivas y articuladas de los participantes en el transcurso de un proceso concreto de enseñanza y aprendizaje. De este modo, el análisis de las formas de la interactividad se convierte en nuestro planteamiento en un elemento imprescindible para abordar el estudio de los mecanismos de influencia educativa.

(ii) $\mathrm{El}$ análisis de la interactividad debe respetar al menos dos exigencias básicas. En primer lugar, debe tener en cuenta la dimensión temporal del proceso de enseñanza y aprendizaje, es decir, debe permitir ubicar las actuaciones de los participantes en el flujo de la actividad conjunta. En efecto, tan importante o más que analizar las actuaciones de los participantes en el transcurso de un proceso de enseñanza y aprendizaje es tener en cuenta el momento del mismo en el que se producen. Actuaciones o comportamientos aparentemente idénticos pueden tener significaciones completamente diferentes desde la perspectiva de los mecanismos de influencia educativa según el momento del proceso en el que aparecen. Igualmente, es necesario, para proceder al análisis de la interactividad, definir de manera explícita y teóricamente coherente un conjunto de unidades de análisis al efecto, que permita señalar a qué tipo(s) de segmento(s) de actividad conjunta hay que aplicar las dimensiones del análisis de la interactividad.

El reconocimiento de ambas exigencias ha pesado fuertemente, como se verá más adelante, en el diseño general del proyecto $y$, muy especialmente, en el tipo de situaciones de observación utilizadas para la recogida de da. tos y en los procedimientos de análisis de los mismos. Son precisamente estas consideraciones las que nos han llevado a elegir la Secuen- cia Didáctica como unidad básica de observación, análisis e interpretación en todas las investigaciones en curso:

«Si definimos una Secuencia Didáctica como un proceso de enseñanza y aprendizaje en miniatura, esto implica la necesidad de identificar o inferir los principales componentes de un proceso de enseñanza y aprendizaje (...): objetivos educativos concretos, utilización de un determinado material, determinadas actuaciones del enseñante cuyo destinatario es el alumno, determinadas actuaciones del alumno sobre el material en torno a los objetivos y contenidos propuestos por el enseñante, determinadas expectativas del enseñante a propósito de las actuaciones del alumno, posibilidad de proceder a una evaluación de las actividades del alumno en función de las expectativas del enseñante. Así pues, para poder hablar de una Secuencia Didáctica tendremos que identificar inequívocamente su inicio, su desarrollo y su finalización.

(Coll, 1983, p. 27)

(iii) El concepto de interactividad, tal como lo hemos dibujado, subraya la importancia del contenido y/o de la tarea en torno a los cuales se articula la actividad conjunta de los participantes. En efecto, la manera como el profesor y los alumnos organizan su actividad conjunta no es independiente de la naturaleza del contenido sobre el que están trabajando o de las exigencias de la tarea que están llevando a cabo. Este principio está en el origen de la decisión de seleccionar y diseñar, para su posterior observación y análisis, secuencias didácticas que versan sobre contenidos y/o tareas de naturaleza y estructura netamente contrastadas. No menor ha sido su influencia, por otra parte, en lo que concierne a los. esfuerzos desplegados para elaborar un procedimiento de análisis de las formas de organización de la actividad conjunta respetuoso con las exigencias y condicionantes impuestos por la naturaleza del contenido y/o la estructura de las tarea en torno a los cuales gira precisamente dicha actividad conjunta.

(iv) La estructura de la actividad conjunta no es algo definido de antemano de forma más o menos consciente y formal por el profesor desde el inicio del proceso de enseñanza y aprendizaje e imputable, por lo tanto, a 
sus ideas pedagógicas y a su estilo de enseñanza. La interactividad, la interrelación de las actuaciones del profesor y de los alumnos en torno a una tarea o contenido de aprendizaje, se construye en el transcurso de las aportaciones respectivas. Probablemente, estamos en realidad en presencia de un doble proceso de construcción: por una parte, los alumnos y alumnas llevan a cabo unos aprendizajes, construyen unos significados relativos a los contenidos que se trabajan en la secuencia didáctica; por otra parte, profesor y alumnos «construyen», como señalan Green, Weade y Graham (1988), la interacción o la actividad conjunta a medida que avanza la secuencia didáctica. La construcción del conocimiento que llevan a cabo los alumnos se inscribe así en un proceso de construcción más amplio en el que aparecen implicados profesor y alumnos y que tiene que ver con el conjunto de las actuaciones de uno y otros, es decir, con lo que hacen y lo que dicen todos los participantes.

En suma -y esta afirmación constituye una de las hipótesis directrices más importantes del proyecto de investigación- - las formas de organización de la actividad conjunta, las modalidades de interactividad en cuyo marco tiene lugar, cuando lo tiene, el proceso de construcción del conocimiento de los alumnos, son en sí mismas el resultado de un proceso de construcción que implica por igual al profesor y a los alumnos. Lo cual, por otro lado, no excluye que en esta construcción las aportaciones de cada uno de ellos sean a menudo asimétricas y que, por descontado, en las aportaciones del profesor puedan jugar un papel decisivo, entre otros factores, sus ideas pedagógicas y su estilo de enseñanza.

(v) La actividad discursiva de los participantes, considerada en el marco más amplio de lo que hacen, o mejor aún, considerada como parte integrante de lo que hacen, constituye un factor de primer orden en la construcción de la actividad conjunta. Por ello, el discurso educacional se convierte en uno de los ejes fundamentales del análisis de los mecanismos de influencia educativa. Conviene insistir, con todo, en que se trata de buscar una aproximación al análisis del discurso educacional que no contrapone la actividad lingüística o discursiva a la actividad no discursiva, sino que considera más bien a ambas como componentes esenciales de la actividad conjunta que despliegan los participantes.

En este sentido, en el intento de avanzar en la comprensión de los mecanismos de influencia educativa, el discurso educacional no es objeto de interés en sí mismo - aunque no ignoramos que pueda serlo desde una perspectiva estrictamente lingüística o incluso sociolingǘstica-, sino más bien en tanto que ingrediente esencial de la actividad conjunta. No creemos posible desvelar dichos mecanismos únicamente a partir del análisis del discurso educacional, por muy complejos y refinados que sean los instrumentos que se utilicen, si se insiste en mantener la frecuente disociación entre actividad discursiva y no discursiva. El reto, pues, en las coordenadas en que nos situamos, consiste en encontrar una aproximación teórica, y muy especialmente una aproximación metodológica, que posibilite un análisis y una interpretación integrados de la actividad discursiva y de la actividad no discursiva en el marco más amplio del flujo de la actividad conjunta. Como veremos más adelante, este reto impregna totalmente nuestra propuesta de unidades y niveles de análisis. $Y$ es que, como señalan Edwards y Mercer (1988, p. 23),

(...) nos interesa lo que las personas se dicen unas a otras, de qué hablan, qué palabras utilizan, qué dan a entender, y también la problemática de cómo establecen esos entendimientos y se construye a partir de ellos según se desarrolla el discurso. Esto significa que nos preocupa no sólo el discurso en sí, sino también aquellas actividades y marcos no lingüís. ticos que constituyen el contexto dentro del cual tiene lugar el discurso.

(Subrayado añadido)

(vi) Uno de los aspectos del discurso de los participantes que ha tenido fuerte influencia sobre el planteamiento del proyecto - sobre todo en lo que ese refiere a los criterios para diseñar y seleccionar las situaciones de observación y de recogida de los datos-- es el recurso por su parte a dos universos experienciales que hemos denominado, respectiva- 
mente, marco social y marco especifico de referencia.

Con la expresión «marco social de referencia» queremos aludir al hecho de que, con relativa frecuencia, el profesor, y en menor medida los propios alumnos, introducen en sus verbalizaciones experiencias o conocimientos no directamente relacionados con el contenido concreto de la secuencia didáctica dando por supuesto que sus interlocutores los comparten. El calificativo de «social» quiere subrayar la idea de que el carácter supuestamente compartido de dichas experiencias y conocimientos reposa en último término sobre la hipótesis - casi siempre implícita, por supuesto- por parte de quien los introduce de que comparte una serie de vivencias y de aprendizajes previos con sus interlocutores por el simple hecho de que éstos forman parte de su mismo grupo social y participan de su misma cultura. El recurso al marco social de referencia se produce, por ejemplo, cuando un profesor que intenta explicar las características del teclado de un ordenador a un grupo de alumnos universitarios comienza señalando que «es lo mismo que en una máquina de escribir», dando por supuesto que los alumnos poseen un conocimiento y una experiencia sobre las máquinas de escribir.

Con la expresión «marco específico de referencia», queremos aludir al hecho de que, también con relativa frecuencia, profesor y alumnos introducen en sus verbalizaciones experiencias o conocimientos directamente relacionados con el contenido concreto de la secuencia didáctica dando por supuesto que sus interlocutores los comparten. El calificativo de «específico» se debe, en este caso, a que el carácter supuestamente compartido de dichas experiencias y conocimientos reposa en último término sobre la hipótesis - de nuevo, casi siempre implícita- por parte de quien los introduce de que comparte una serie de vivencias y de aprendizajes previos con sus interlocutores por el simple hecho de que éstos han participado en la misma secuencia didáctica. El recurso al marco específico de referencia se produce, por ejemplo, cuando un profesor que está enseñando la utilización de un procesador de textos a un grupo de alum- nos universitarios les explica cómo «cambiar el formato del párrafo seleccionado», dando por supuesto que los alumnos conocen ya qué es el «formato de un párrafo» y el procedimiento de «seleccionar un párrafo» debido a que estos aspectos han sido objeto de estudio y de práctica en una sesión anterior de la misma secuencia didáctica.

Nuestras conjeturas se orientan en la dirección de suponer que el mayor o menor recurso al marco social de referencia depende de variables o factores que están, al menos en parte, estrechamente vinculados con la dimensión temporal de la actividad conjunta. Así, por ejemplo, cabe postular que el recurso al marco social de referencia como punto de arranque para establecer un contexto mental compartido será más frecuente al inicio de una secuencia didáctica, cuando los participantes no comparten nada o casi nada del marco específico de referencia, que al final de la misma, cuando los participantes pueden confiar razonablemente en las experiencias - supuestamente- compartidas sobre el contenido ya trabajado o las tareas ya realizadas para poder construir con relativa facilidad nuevas comprensiones conjuntas. Del mismo modo, cabe pensar que el recurso al marco social de referencia por parte del profesor será tanto más frecuente cuanto menor sea el conocimiento que sobre el contenido o las tareas a desarrollar en la secuencia didáctica tengan - una vez más supuestamente - sus alumnos; y a la inversa, que será tanto menor cuanto más dominio del contenido o de las tareas atribuya a sus alumnos. Por último, cabe también formular la hipótesis de que, cuando el profesor se percata de que se ha producido una incomprensión o un malentendido a propósito de algún aspecto del contenido o de la ejecución de una tarea, la posibilidad de referirse a experiencias extraescolares con las que puedan identificarse --de nuevo supuestamente- los alumnos deviene un procedimiento importante para restablecer un contexto mental compartido sobre el cual relanzar la construcción de comprensiones conjuntas.

(vii) Desde una perspectiva constructivista, en que el aprendizaje escolar se concibe 
como un proceso de construcción de significados y de atribución de sentidos cuya responsabilidad última corresponde al alumno, la influencia educativa que trata de ejercer el profesor cuando enseña sólo puede entenderse

«en términos de ayuda prestada a la actividad constructiva del alumno; y la influencia educativa eficaz en términos de un ajuste constante y sostenido de esta ayuda a las vicisitudes del proceso de construcción que lleva a cabo el alumno. Conviene subrayar el doble sentido del concepto de ayuda pedagógica. Por una parte, es sólo una ayuda porque el verdadero artífice del proceso de aprendizaje es el alumno; es él quien va a construir los significados y la función del profesor es ayudarle en ese cometido. Pero, por otra parte, es una ayuda sin cuyo concurso es altamente improbable que se produzca la aproximación deseada entre los significados que construye el alumno y los significados que representan y vehiculan los contenidos escolares.»

(Coll, 1990, p. 448)

Si concebimos la construcción del conocimiento que subyace al aprendizaje escolar como un proceso, entonces la ayuda pedagógica ha de concebirse también como un proceso. De ahí que, a nuestro juicio, no pueda asimilarse la concepción constructivista con una metodología didáctica particular. No creemos que exista una metodología didáctica constructivista; lo que hay es una estrategia didáctica general de naturaleza constructivista que se rige por el principio de ajuste de la ayuda pedagógica y que puede concretarse en múltiples metodologías didácticas particulares según el caso. El profesor capaz de promover en sus alumnos aprendizajes con un alto grado de significatividad y funcionalidad es el profesor que, entre otros extremos, puede utilizar de forma flexible, atendiendo a las características concretas de cada situación, la gama más o menos amplia de recursos didácticos de que dispone. Al hablar de los mecanismos de influencia educativa que se manifiestan en, o actuan a través de, la interacción entre el profesor y los alumnos, nos estamos refiriendo precisamente a los mecanismos que hacen posible este ajuste -en el caso, por supuesto, de que se produzca, lo que no está ni mucho menos garantizado de entrada - entre, por una parte, la ayuda pedagógica del profesor, y por otra, el proceso de construcción del conocimiento de los alumnos.

(viii) La cesión y traspaso progresivos de la responsibilidad y del control en el aprendizaje puede hipotetizarse como uno de los mecanismos de influencia educativa cuya identificación persigue nuestro proyecto. A este proceso remite la metáfora del «andamiaje» introducida por Bruner y sus colaboradores (Wood, Bruner y Ross, 1976) para explicar los procesos de avance de los niños a través de las Zonas de Desarrollo Próximo que se crean en sus interacciones con los adultos. Igualmente, remiten a este proceso, con distintas formas y matices, diversos trabajos de análisis de la interacción diádica adulto-niño (Wertsch, 1979, 1988; Wood, Wood y Middleton, 1978; Wood, 1980; Rogoff, 1984, 1990).

Sin embargo, lo habitual en el contexto escolar es la situación en la que un profesor interactúa con un grupo de alumnos. Este hecho obliga a algunas reservas y explica, por ejemplo, la prudencia de Cazden cuando afirma que

«a causa de los problemas inherentes a un buen ajuste en la instrucción simultánea de un grupo de niños, lo que mejor se adapta a este modelo probablemente sean, la mayoría de las veces, las interacciones del maestro con alumnos individuales.»

$$
\text { (Cazden, 1991, p. }
$$

Surgen así una serie de preguntas concretas a las que únicamente el análisis de los datos empíricos puede aportar elementos de respuesta: ¿es posible encontrar indicadores de una cesión progresiva del control por parte del profesor y de una asunción progresiva de la responsabilidad por parte de los alumnos en las secuencias didácticas registradas?; en caso afirmativo, ¿es posible identificar los dispositivos - o al menos algunos de ellos- mediante los cuales se produce la cesión del control y el correspondiente traspaso de la responsabilidad?; ¿qué sucede cuando la cesión del control es precipitada o inapropiada y los alumnos no pueden asumir la responsabilidad correspondiente?; ¿qué papel juegan a este 
respecto algunos factores como la estructura de la tarea, la naturaleza del contenido u otros que hemos ido señalando en los epígrafes precedentes?; etc. He aquí algunas de las preguntas que, a partir de la hipótesis de la cesión y el traspaso progresivos de la responsabilidad y del control, hemos formulado al conjunto de investigaciones que conforman el proyecto.

(ix) El aprendizaje escolar puede interpretarse como un proceso de construcción progresiva de sistemas de significados compartidos a propósito de las tareas, situaciones o contenidos en torno a los cuales se organiza la actividad conjunta de los participantes. La construcción progresiva de significados compartidos que tiene lugar en un proceso educativo - escolar o extraescolar - presenta similitudes, por una parte, con el proceso mediante el cual dos interlocutores cualesquiera llegan a ponerse de acuerdo sobre el significado que posee un enunciado en un determinado contexto, y por otra parte, con el proceso de negociación que se produce entre los participantes en la interacción en el marco de la Zona de Desarrollo Próximo.

En relación con el primer proceso, y siguiendo el análisis efectuado por Nelson (1988), cada interlocutor lleva a cabo su interpretación del enunciado a partir de su propio sistema cognitivo; es decir, establece un significado subjetivo a partir de su propio sistema de interpretación de significados. Para ponerse de acuerdo, es necesario que ambos interlocutores lleguen a establecer un sistema de significados compartidos formado por las parcelas coincidentes de sus respectivos significados subjetivos. Cuando entre éstos no existen parcelas coincidentes, el resultado es la incomprensión absoluta; y a la inversa, cuando los significados subjetivos muestran una total coincidencia, la comprensión es total. Lo habitual, sin embargo, es que el grado de coincidencia comience siendo más bien bajo y que vaya incrementándose de forma paulatina merced a los intercambios comunicativos entre los interlocutores. Los interlocutores llegan a establecer un sistema de significados compartidos mediante la aproximación o adecuación progresiva de sus respectivos sistemas de interpretación de significados a las representaciones convencionales del grupo cultural al que pertenecen.

En relación con el segundo de los procesos citados, y de acuerdo con las reflexiones formuladas por Wertsch (1984), el adulto y el niño que se implican conjuntamente en la ejecución de una tarea o en el desarrollo de una actividad tienen, cada uno por su parte, una definición de la situación, es decir, se representan de una determinada manera la situación y el conjunto de acciones a ejecutar en la misma. Esta definición intrasubjetiva de la situación es probablemente diferente para ambos. Para que pueda establecerse la comunicación es necesario un cierto nivel de intersubjetividad: los dos deben compartir, aunque sea parcialmente, una definición de la situación y, además, deben saber que la comparten. Así pues, o bien no se establecerá la comunicación, o bien es imprescindible que se produzca una negociación que desemboque en una definición intersubjetiva inicial de la situación. Adulto y niño participan activamente en la negociación, pero su papel, nos advierte Wertsch, es claramente asimétrico: mientras el cambio que el adulto introduce en su definición intrasubjetiva de la situación es el fruto de una estrategia para establecer la comunicación y, por lo tanto, es un cambio temporal, el que se produce en la definición in trasubjetiva del niño es permanente, o se espera que lo sea, en la medida en que el adulto trata de «arrastrarlo» hacia su propia definición con fines educativos o instruccionales. Según el autor, el proceso que permite la negociación entre los dos participantes y el establecimiento de una definición intersubjetiva de la situación depende de que se utilicen «formas apropiadas de mediación semiótica».

Surge así un nuevo conjunto de interrogantes que el análisis de las observaciones tendrá que afanarse en responder: esta descripción hipotética, esta interpretación elaborada esencialmente (una vez más) para dar cuenta de lo que sucede en situaciones de interacción diádica, ¿es aplicable a lo que sucede en las situaciones en las que el profesor interactúa con un grupo de alumnos en el 
aula?; ¿es posible encontrar indicadores empíricos de una construcción progresiva de sistemas de significados compartidos en las secuencias didácticas registradas?; en caso afirmativo, ¿es posible identificar los dispositivos o procedimientos - $\mathrm{o}$ al menos algunos de ellos- que la hacen posible?; ¿es posible detectar rupturas, divergencias o malentendidos en la construcción de sistemas de significados compartidos?; ¿mediante qué procedimientos se consigue el establecimiento de una definición intersubjetiva inicial de la situación a partir de la cual iniciar la construcción de sistemas de significados compartidos cada vez más amplios?; juega algún papel en la definición intersubjetiva inicial de la situación, y también en la posterior construcción de sistemas de significados compartidos, la utilización que hacen los participantes de lo que hemos llamado en un epígrafe anterior el marco social de referencia y el marco específico de referencia?; etc.

(x) El análisis de las formas de organización de la actividad conjunta y de su evolución a lo largo de las secuencias didácticas puede llevarse a cabo, por así decirlo, a distintos niveles de profundidad y con diferentes propósitos. En lo que nos concierne, el enfoque adoptado nos lleva a distinguir, en una primera aproximación, dos niveles de análisis con dos propósitos claramente definidos.

El primero se centra en la articulación de las actuaciones del profesor y de los alumnos en torno a la tarea o contenido de aprendizaje y en su evolución a lo largo de la secuencia didáctica. Es un análisis que se sitúa necesariamente en un nivel «macro» y que presenta, como principal dificultad metodológica, la exigencia de una categorización de las actuaciones de los participantes que sea suscep. tible de reflejar su mayor o menor interconexión, que permita detectar una posible evolución de las mismas a lo largo de la secuencia didáctica y que atienda a la naturaleza de los contenidos abordados y/o de las tareas desarrolladas. Un análisis de este tipo parece a priori adecuado, entre otros extremos, para aportar elementos de respuesta a las cuestiones antes formuladas sobre la cesión y el traspaso progresivos del control y la responsabi- lidad en el transcurso de las secuencias didácticas.

El segundo nivel de análisis, por su parte, es una consecuencia de la importancia otorgada a la actividad discursiva de los participantes y se vincula, siguiendo la recomendación de Wertsch, a las formas de mediación semiótica utilizadas. Este análisis, de naturaleza mucho más «micro» que el anterior, tiene como propósito aportar elementos de respuesta a las cuestiones antes formuladas sobre la construcción progresiva de sistemas de significados compartidos a lo largo de las secuencias didácticas. Desde el punto de vista metodológico, plantea la exigencia, con todas las dificultades que ello supone, de encontrar un procedimiento de análisis susceptible de dar cuenta de los significados que transmiten o vebiculan los participantes mediante su actividad discursiva y que se someten, de esta manera, a una posible negociación y modificación.

En el apartado relativo a las unidades y niveles de análisis describiremos los procedimientos mediante los cuales se intenta hacer frente a estos propósitos y exigencias. Por el momento, añadiremos sólo que ambos análisis deben tener un carácter complementario y deben llevarse a cabo de tal manera que sus resultados respectivos se apoyen y se enriquezcan mútuamente en aras de una interpretación integrada. Esta exigencia añadida tiene un doble origen. Por una parte, el rechazo frontal a disociar la actividad discursiva de los participantes - qué dicen y cómo lo dicen- de su actividad no discursiva - qué hacen y cómo lo hacen- y la convicción de que el estudio de los mecanismos de influencia educativa requiere que ambos tipos de actividad sean considerados de forma interrelacionada en el marco más amplio de la actividad conjunta. Por otra parte, la necesidad de encontrar una relación teóricamente fundamentada entre el proceso de cesión y traspaso progresivos del control y la responsabilidad, que constituye el propósito fundamental del primer tipo de análisis, y el proceso de construcción progresiva de un sistema de significados compartidos, que constituye el propósito fundamental del segundo. 
(xi) Hasta el momento, nuestra argumentación se ha referido esencialmente al «prendizaje formal» y a la «actividad escolar», una de las tres actividades y uno de los tres contextos sociales e institucionales típicos -junto con el juego y la actividad lúdica y el trabajo y la actividad laboral- a los que tradicionalmente se ha prestado mayor atención (Leontiev, 1981; Griffin y Cole, 1984; Wertsch, 1988). En este sentido, cabe suponer que la actividad conjunta de los participantes en una secuencia didáctica que tiene lugar en la escuela está esencialmente orientada por el motivo de enseñar y aprender -inherente al «contexto situacional institucionalmente definido» en el que se inscribe la secuencia didáctica-, siendo este motivo el que determina en último término el significado funcional de las actuaciones de los participantes, es decir, aquello a lo que se debe prestar atención y aquello que se puede pasar por alto o que tiene una importancia secundaria. De ahí nuestro interés prioritario por indagar, en las formas de organización de la actividad conjunta, los procesos de cesión y traspaso progresivos del control y la responsabilidad y de construcción progresiva de sistemas de significados compartidos, ya que ambos procesos pueden ser relacionados a nivel teórico con el motivo de la actividad escolar formal, es decir, con el motivo de enseñar y aprender.

Sucede a menudo, sin embargo, que el contexto situacional de la actividad no está de entrada tan bien definido para los participantes como en el caso de un profesor y un grupo de alumnos que llevan a cabo una secuencia didáctica en el aula en torno a un contenido o una tarea típicamente escolares. Incluso en el ámbito escolar, sobre todo en los niveles de la educación preescolar y primaria, podemos encontrar numerosos ejemplos de situaciones en las que profesores y alumnos llevan a cabo actividades conjuntas sin que sea posible discernir con claridad si responden a un motivo de aprendizaje formal o de juego; o en las que el profesor y los alumnos despliegan de hecho dos tipos de actividad con motivos claramente distintos: de aprendizaje formal en el primer caso y de juego en el segundo.
Imaginemos el caso extremo de un padre o una madre que están mirando un libro de imágenes con su hijo, leyéndole un cuento, comentando un episodio de dibujos animados que ofrece la televisión, o simplemente representando una historia con la ayuda de unas pequeñas marionetas. Es muy posible que, en situaciones de esta naturaleza, el niño aborde la actividad conjunta con la única finalidad de jugar, mientras que el padre o la madre, sin renunciar al componente de juego, pretendan de forma más o menos consciente y planificada aprovechar la coyuntura para «enseñarle» algo relativo a los objetos, situaciones o sucesos que aparecen en las imágenes, el cuento, los dibujos animados o la historia representada. Más aún, es posible que en determinadas circunstancias la actividad conjunta acabe derivando netamente hacia una actividad de juego, mientras que en otras ocasiones lo haga hacia una actividad de aprendizaje más o menos formal.

El estudio de los mecanismos de influencia educativa que operan supuestamente en situaciones de esta naturaleza - la suposición no parece demasiado arriesgada y se justifica fácilmente a partir de los resultados de investigaciones realizadas en situación natural - no puede llevarse a cabo sobre los mismos supuestos y con las mismas hipótesis directrices que en el caso de actividades de naturaleza inequívocamente escolar. En este último caso, nuestro razonamiento nos ha llevado a formular conjeturas y a plantear preguntas concretas sobre cómo se organiza la actividad conjunta de los participantes con el fin de que los contenidos y/o la ejecución de las tareas en torno a los cuales gira la secuencia didáctica puedan ser efectivamente enseñados y aprendidos. Cuando el contexto situacional de la actividad no aparece de entrada claramente definido, el estudio de los mecanismos de influencia educativa requiere, por así decirlo, un paso previo: indagar cómo y en qué sentido va definiéndose progresivamente el contexto situacional de la actividad; o si se prefiere, indagar cómo los participantes van creando progresivamente, mediante la articulación de sus actuaciones respectivas, 
un contexto situacional de actividad determinado.

La inclusión de algunas situaciones de esta naturaleza en un proyecto de investigación sobre los mecanismos de influencia educativa tiene pues un interés evidente. Por una parte, pueden ofrecernos datos sobre algunos aspectos de la organización de la actividad conjunta que no es previsible que puedan obtenerse únicamente a partir de la observación de secuencias didácticas de carácter típicamente escolar, en las que el contexto situacional de la actividad aparece claramente definido de entrada. Por otra parte, en una lógica que no aspira a la contrastación pero sí a la diversidad y a la heterogenidad de las situaciones observadas atendiendo a parámetros teóricamente relevantes, pueden ofrecer un contrapunto para la interpretación, en términos de mecanismos de influencia educativa, de los procesos de cesión y traspaso progresivos del control y la responsabilidad y de construcción progresiva de significados compartidos.

\section{EL DISEÑO DEL PROYECTO: SITUACIONES DE OBSERVACION $Y$ PROCEDIMIENTO DE RECOGIDA DE DATOS}

Todas las investigaciones incluidas en el proyecto comparten la característica de utilizar la Secuencia Didáctica (SD) denominada Secuencia de Actividad Conjunta (SAC) cuando el contexto social e institucional de la actividad es de naturaleza no escolar - como unidad básica de recogida de datos, atendiendo de este modo a las exigencias expuestas en el punto (ii) de la exposición del marco teórico. Este hecho refleja la importancia otorgada a la dimensión temporal, y más concretamente a la ubicación de las actuaciones de los participantes en el flujo de la actividad conjunta, como uno de los aspectos esenciales a tener en cuenta para la identificación y comprensión de los mecanismos de influencia educativa.

En el diseño de las situaciones de observación se ha intentado respetar al máximo las condiciones habituales y el contexto natural en el que los participantes despliegan normalmente su actividad. En la mayoría de los casos, se ha procedido simplemente a seleccionar, atendiendo a una serie de criterios, situaciones habituales de actividad conjunta, limitándose la intervención de los investigadores a negociar todos aquellos aspectos susceptibles de facilitar el proceso de observación y registro de los datos y de garantizar su fiabilidad y su pertinencia para los objetivos del proyecto. Cuando esto no ha sido posible y se han tenido que crear situaciones ad hoc para registrar determinados tipos de actividad conjunta - es el caso, por ejemplo, de las SD del procesador de textos y de las SAC de los gnomos que se describen más abajo-, se ha intentado reducir al máximo la artificialidad de las condiciones dejando a los participantes un amplio margen de maniobra en la definición de la situación y, sobre todo, en el desarrollo de la actividad.

Las situaciones de observación han sido diseñadas o seleccionadas de tal manera que, consideradas en su globalidad, hacen intervenir un conjunto de variables o factores potencialmente relevantes -- de acuerdo con las ideas directrices y los principios básicos expuestos en el apartado anterior- para el análisis de los mecanismos de influencia educativa. Las variables que se han tomado en consideración en el conjunto de investigaciones incluidas en el proyecto son las siguientes:

Participantes: profesor/grupo de alumnos; dos o más alumnos trabajando en grupo; madre/niño(a); dos niños/as manipulando un material de juego.

Edad de los niños/alumnos: desde 3 años a estudiantes universitarios. Conviene señalar que la inclusión de esta variable en el diseño general de las situaciones de observación no responde a un interés por detectar diferencias de tipo evolutivo, sino más bien a la idea de que la edad está asociada con «marcos sociales de referencia» de amplitud y complejidad diversa.

Contexto social e institucional: contexto escolar; contexto familiar; contexto de juego.

Contenido/tareas de las SD/SAC: contenidos matemáticos; contenidos de ciencias natura- 
les; contenidos de ciencias sociales; procesador de textos; contenidos no escolares.

Conocimientos previos de los niños/alumnos: con conocimientos previos sobre el contenido/tarea de la actividad conjunta; sin cono. cimientos previos sobre el contenido/tarea de la actividad conjunta. Nótese que, de acuerdo con nuestro planteamiento teórico, el interés de esta variable reside sobre todo en poder detectar hasta qué punto un participante en la actividad conjunta (por ejemplo, el profesor) tiene en cuenta lo que saben supuestamente otros participantes (por ejemplo, los alumnos) y en qué medida esta suposición interviene en las interacciones que se establecen entre ellos. Esta es la razón por la cual, en las investigaciones en las que interviene esta variable, los grupos no se diferencian únicamente por el hecho de tener o no tener conocimientos previos sobre el contenido o tarea a realizar, sino también y sobre todo porque los otros participantes en la actividad conjunta son informados al respecto.

En todas las SD/SAC se ha seguido, en términos generales, el mismo procedimiento de recogida de datos. Tras una primera fase durante la cual se negocia el contenido a trabajar y/o la tarea a desarrollar por los participantes, las condiciones en que va a llevarse a cabo la observación y el uso confidencial de los registros, se procede a una sesión de prueba con el fin de que participantes y observadores se familiaricen con la situación. Seguidamente, se procede a entrevistar a los participantes. En el caso de los profesores, la entrevista tiene como finalidad obtener in. formación sobre los objetivos que se proponen alcanzar, los contenidos concretos que van a trabajar, la metodología y materiales que tienen previsto utilizar, las actividades de enseñanza y aprendizaje que van a proponer a sus alumnos, las expectativas sobre los resultados de aprendizaje, las dificultades con las que previsiblemente van a encontrarse y cómo piensan actuar para superarlas. En el caso de los alumnos/niños, la entrevista toma esencialmente la forma de una evaluación inicial de sus conocimientos sobre el contenido y/o la tarea que es objeto de atención en la $\mathrm{SD} / \mathrm{SAC}$. Igualmente, en el caso de las ma- dres, esta entrevista inicial trata de indagar los conocimientos sobre el contenido en torno al cual va a organizarse la actividad conjunta.

$\mathrm{El}$ paso siguiente consiste en un registro audio o vídeo - con o sin registros audio y narrativo complementarios, según los casosde todas las sesiones de actividad conjunta que conforman la SD/SAC. Finalmente, se procede a entrevistar de nuevo a los participantes. En el caso de los profesores y madres, esta segunda entrevista se centra en su valoración de lo sucedido en el transcurso de la $\mathrm{SD} / \mathrm{SAC}$ y en una comparación entre las previsiones realizadas en la entrevista inicial y lo efectivamente acontecido. En el caso de los alumnos/niños, el objetivo es más bien detectar si se han producido cambios significativos respecto a la evaluación inicial en cuanto al dominio de las tareas y/o al conocimiento de los contenidos trabajados.

Conviene insistir sobre el hecho de que el diseño general de las investigaciones que conforman el proyecto no responde a una lógica contrastiva. La finalidad no es comparar $\mathrm{SD} / \mathrm{SAC}$ que difieren entre sí en las variables o factores mencionados, sino más bien analizar la evolución de la actividad conjunta en el interior de cada una de ellas. La selección y/o diseño de SD/SAC contrastadas en lo que concierne a estas variables of factores tiene como objetivo principal facilitar la posible aparición, y la observación, registro y análisis subsiguientes, de un abanico lo más amplio posible de mecanismos de influencia educativa y de manifestaciones distintas de los mismos.

A continuación se describen brevemente tres de las siete investigaciones incluídas en el proyecto que, además de servirnos como punto de referencia para ejemplificar el modelo de análisis que expondremos más adelante, constituyen otras tantas concreciones ilustrativas del mismo planteamiento metodológico general.

\section{La enseñanza y el aprendizaje de la numeración y de algunas operaciones elementales de cálculo}

Las SD registradas en este caso corresponden a dos clases de preescolar, una de prime- 
ro (P4) y otra de segundo (P5), de una escuela pública de Sant Boi del LLobregat, una población del cinturón industrial de Barcelona. Las profesoras de preescolar y de ciclo inicial de este centro han decidido desde hace ya algunos años, de común acuerdo y con el apoyo de una profesional del Equipo de Asesoramiento Psicopedagógico de la zona, adoptar una metodología didáctica basada en los rincones de juego para trabajar objetivos y contenidos de cálculo. Concretamente, en el caso de preescolar, las profesoras trabajan de este modo el aprendizaje de la serie de números naturales (hasta el 10), la comparación de números, las correspondencias, la adición (únicamente en P5) y la composición y descomposición de números. Para ello, los alumnos y alumnas ( 30 por clase) son distribuidos en cinco grupos de seis niños cada uno. Cada grupo trabaja alrededor de una mesa en la que se encuentra un juego de tablero o de cartas. Los juegos utilizados son adaptaciones realizadas por las mismas profesoras a partir de los juegos propuestos por Kamii (1985) para estos niveles educativos. Los grupos trabajan con el mismo juego durante tres sesiones y después se produce una rotación, de tal manera que al final todos los grupos pasan por el conjunto de juegos programados. Seguidamente, se cambian los juegos por otros nuevos y recomienza el proceso.

Las profesoras organizan la actividad de los grupos con cada juego en tres fases que tienen lugar en otras tantas sesiones. En la primera, explican las reglas, hacen algunas demostraciones, aclaran las dudas que surgen y dirigen alguna/s partida/s de prueba para asegurarse de que los niños y las niñas han entendido el juego. En la segunda, los niños y niñas juegan solos y la profesora se pasea entre las mesas supervisando su desarrollo e interviniendo si se cometen errores o si cree oportuno realizar algún comentario. En la tercera, la profesora evalúa hasta qué punto se han alcanzado los objetivos propuestos observando el desarrollo de una partida y utilizando una ficha de evaluación que deben cumplimentar todos los miembros del grupo.

Los datos registrados corresponden a la actividad desplegada por sendos grupos de P4 y de P5 con seis y cinco juegos distintos respectivamente. Se dispone pues de información sobre seis Secuencias Didácticas sucesivas de un grupo de P4 y cinco Secuencias Didácticas sucesivas de uno de $\mathrm{P}$, correspondiendo en este caso una SD a las tres sesiones que un grupo trabaja con el mismo juego. Las sesiones de P4 tienen una duración media aproximada de 30 minutos, mientras que las de P5 son un poco más largas. Todas las sesiones han sido objeto de un registro audio (verbalizaciones de los participantes) y de un registro narrativo (descripción de las acciones y del contexto). Estos datos se complementan con las entrevistas iniciales y finales de las profesoras (registro audio) y con la información contenida en una memoria sobre la organización de los rincones de matemáticas elaborada por ellas mismas previamente a nuestra llegada a la escuela. No se ha considerado necesario, en este caso, efectuar entrevistas iniciales y finales a los alumnos.

Los cambios introducidos por las exigencias de la investigación en la dinámica habitual de las clases han sido mínimos. Los únicos aspectos negociados con las profesoras han sido mantener sin cambios la composición de los dos grupos observados y realizar los rincones de matemáticas en las fechas y horas previamente establecidas. Se ha respetado totalmente la selección, secuenciación y temporalización de los juegos establecidas por las profesoras en sus programaciones. Ellas han decidido la composición de los grupos -utilizando un criterio de heterogeneidady han seleccionado los dos grupos objeto de observación en las sucesivas SD.

\section{La construcción de un entorno ficticio: el mundo de los gnomos}

Esta investigación se sitúa en el contexto familiar y los sujetos son niños y niñas de edades comprendidas entre los 3 y los 6 años observados en situación de interacción diádica con sus respectivas madres en torno al mundo ficticio de los gnomos. Los datos registrados corresponden a seis parejas madre-hijo/a; en dos de ellas el hijo/a tiene una edad de 3 
años y 6 meses; en otras dos, 4 años y 6 meses; y en las otras dos, 5 años y 6 meses. Todas las parejas provienen de un medio socioeconómico y cultural de clase media. Se han utilizado dos tipos de material para la realización de la experiencia: seis montajes de vídeo confeccionados a partir de las cintas de la serie de T.V. «David el gnomo» ${ }^{4}$ y material manipulable (figuras que representan gnomos y gnomas, trolls, animales de distintas especies y seres humanos, árboles, casas, puentes, etc.) relativo al entorno de los gnomos.

El procedimiento utilizado es el mismo con todas las parejas y se lleva a cabo en ocho sesiones con una periodicidad aproximadamente semanal. La primera y la última estan de. dicadas a la evaluación inicial y final respectivamente del conocimiento de los niños y niñas sobre el entorno de los gnomos y sus características. Las madres son también objeto de la evaluación inicial así como de una entrevista final. Las seis sesiones restantes, que constituyen la Secuencia de Actividad Conjunta (SAC) propiamente dicha, estan organizadas en dos fases. En la primera, la madre y su hijo/a visualizan juntos uno de los montajes de vídeo en el que se narra una historia de gnomos. En cada una de las seis sesiones se presenta un montaje diferente. Los montajes tienen una duración media aproximada de 20 minutos. Seguidamente, en la segunda parte de cada sesión, la madre y su hijo/a juegan con el material simbólico alusivo al entorno de los gnomos. Esta segunda fase tiene también una duración media aproximada de 20 minutos. Las fases de juego de cada sesión están precedidas por una consigna que se da conjuntamente a los dos miembros de la díada; en las tres primeras, consiste simplemente en una invitación a jugar ( «Después de lo que habéis visto, podéis empezar a jugar con estos gnomos y las otras figuritas»); en las tres siguientes, las consignas son más precisas y se refieren siempre a las historias presentadas en el montaje (por ejemplo, «Podéis jugar a qué pasaría si los gnomos y gnomas se encontraran con unos trolls»).

Son pues en total seis las parejas y las Secuencias de Actividad Conjunta observadas.
Para cada una de ellas, se dispone del registro en vídeo de las evaluaciones iniciales y finales de los niños/as, del registro en audio de las evaluaciones iniciales y entrevistas finales de las madres, y finalmente, de los registros vídeo de las dos fases - visualización del montaje y juego- de cada una de las seis sesiones que conforman la SAC propiamente dicha.

\section{La enseñanza y el aprendizaje de un procesador de textos}

Esta investigación se lleva a cabo en situaciones formales de enseñanza y aprendizaje relativas al conocimiento y utilización de un programa de tratamiento de textos (PT). Se han formado cuatro grupos de ocho alumnos cada uno con las siguientes características: (a) grupo de estudiantes universitarios sin experiencia previa en el manejo de ordenadores; (b) grupo de estudiantes universitarios con experiencia previa en el manejo de ordenadores pero sin conocimiento del PT en cuestión; (c) grupo de estudiantes de $8^{\circ}$ de E.G.B. sin experiencia previa en el manejo de ordenadores; y (d) grupo de $8^{\circ}$ de E.G.B. con experiencia previa en el manejo de ordenadores pero sin conocimiento del PT en cuestión.

Los dos grupos de universitarios se han constituido expresamente para la investigación con alumnos de psicología que se han ofrecido a participar de forma voluntaria y sin otra contrapartida que la de aprender el manejo del PT. El profesor, con amplia experiencia docente en cursos de esta naturaleza dirigidos a estudiantes universitarios, es el mismo para los dos grupos. Los grupos de $8^{\circ}$ de E.G.B. proceden de dos escuelas distintas y la experiencia se ha llevado a cabo en el marco de sendas «colonias de informática» en una institución de carácter cultural de la provincia de Barcelona ${ }^{5}$. El profesor, también el mismo para los dos grupos, es el que imparte habitualmente los cursos de informática durante las colonias. Los programas trabajados han sido el WriteNow, en los grupos de universitarios, y el McWrite, en los grupos de $8^{\circ}$ de E.G.B., ambos del entorno Macintosh. 
Las cuatro Secuencias Didácticas - una por cada grupo- han sido planificadas y realizadas siguiendo las mismas pautas generales. En primer lugar, los profesores enseñan el PT en las condiciones y con la metodología didáctica (infraestructura, equipos, duración y número de sesiones, ratio alumnos/ordenador, contenidos, objetivos, etc.) fijadas y decididas por ellos mismos en concordancia con lo que es su manera habitual de proceder. En los grupos de universitarios, los ocho alumnos se distribuyen por parejas y cada pareja tiene a su disposición un ordenador; el profesor dedica cuatro sesiones de dos horas de duración cada una -ocho horas en total- a enseñar el PT. En los grupos de $8^{\circ}$ de E.G.B., la duración es menor: una sesión de dos horas en un grupo y dos sesiones de hora y media aproximadamente en el otro. En todos los casos, los profesores consideran que el tiempo utilizado es suficiente para trabajar los contenidos y alcanzar los objetivos que se han propuesto.

Seguidamente se constituyen cuatro parejas al azar - con la única restricción de que sean distintas a las que han trabajado con el mismo ordenador en las sesiones previascon los ocho alumnos de cada grupo. Cada pareja tiene que resolver, en un plazo máximo de una hora (estudiantes universitarios) o de media hora (estudiantes de $8^{\circ}$ de E.G.B.), una tarea consistente en la corrección de un texto grabado en un fichero para hacerlo idéntico a otro texto impreso ofrecido como modelo. Los cambios a introducir en el texto grabado en el fichero exigen utilizar las diversas funciones y posibilidades del PT que han sido objeto de enseñanza en las sesiones anteriores. A continuación, las mismas parejas realizan una segunda tarea, con los mismos plazos temporales - una hora para los estudiantes universitarios y media hora para los estudiantes de E.G.B.-, consistente en producir un texto libre con unas determinadas características formales que hacen intervenir de nuevo las funciones y posibilidades del PT enseñadas en las sesiones iniciales. Por último, todos los alumnos cumplimentan un cuestionario de elección múltiple cuyos items se refieren a los conceptos, funciones y pro- cedimientos del PT y cuya finalidad es obtener información complementaria sobre los aprendizajes realizados en el transcurso de la SD.

El conjunto de datos para cada SD sobre los que se efectúan los correspondientes análisis son los siguientes: registro audio de las entrevistas iniciales y finales con el profesor; cuestionarios de evaluación final cumplimentados individualmente por todos los alumnos; registro vídeo del conjunto de la clase durante las sesiones de enseñanza y aprendizaje del PT; y registro vídeo de cada una de las cuatro parejas del grupo durante la resolución de las dos tareas propuestas.

\section{EL PROCEDIMIENTO DE ANALISIS: UNA PROPUESTA}

Recordemos que la idea directriz de nuestro planteamiento es que el estudio de los mecanismos de influencia educativa que operan en el nivel de la interacción profesor/grupo de alumnos -o de la interacción diádica entre la madre y su hijo/a, o aún de la interacción entre iguales- debe centrarse en el análisis de las formas de organización de la actividad conjunta. Asimismo, hemos llegado a la conclusión de que este análisis debe integrar la dimensión temporal, debe tener en cuenta la naturaleza del contenido y/o la estructura de la tarea y debe prestar una especial atención a la interrelación existente entre lo que dicen y lo que hacen los participantes en el transcurso de su actividad conjunta. Por último, hemos convenido orientar el análisis hacia la búsqueda de indicadores empíricos interpretables en términos de cesión y traspaso progresivos del control y la responsabilidad y de construcción progresiva de sistemas de significados compartidos. Esto cuando la actividad conjunta tiene lugar en un contex to social e institucional claramente presidido por el motivo de enseñar y aprender, como sucede por ejemplo en las SD de enseñanza y aprendizaje de un procesador de textos descritas en el apartado anterior. Cuando no es así, cuando el contexto situacional de la actividad no aparece de en- 


\section{4}

trada claramente definido - como sucede por ejemplo en las SAC relativas al mundo de los gnomos también descritas en el apartado anterior-, el análisis debe acometer una tarea previa: indagar cómo los participantes van definiendo progresivamente, mediante la articulación de sus actuaciones respectivas, el contexto situacional en el que desarrollan su actividad.

A todo ello hay que añadir, además, que una serie de consideraciones de orden teórico y metodológico nos han llevado a proponer dos tipos de análisis de las formas de organización de la actividad conjunta que se sitúan en diferentes niveles de profundidad y de detalle y que responden a propósitos distintos. Siguiendo una determinada línea de argumentación, hemos sugerido la posibilidad de centrar el primero, de naturaleza más «macro», en la evolución de las actuaciones de los participantes y de sus interrelaciones a lo largo de las SD/SAC, siendo su objetivo fundamental aportar elementos de respuesta a las cuestiones relativas a la cesión y traspaso progresivos del control y la responsabilidad; y el segundo, de naturaleza mucho más «micro» que el anterior, en los significados que actualizan los participantes mediante su actividad discursiva y que son objeto de negociación y modificación, siendo su objetivo fundamental informar sobre cómo se produce, cuando se produce, la construcción progresiva de sistemas de significados compartidos en el transcurso de las SD/SAC. Ambos análisis, por lo demás, han de tener un carácter complemen. tario y deben llevarse a cabo de tal manera que sus resultados respectivos se apoyen y se enriquezcan mútuamente en aras de una interpretación integrada.

El conjunto de procedimientos de análisis que exponemos a continuación, fruto de una serie de ensayos sucesivos, responde en términos generales a las exigencias apuntadas. Como puede comprobarse, subsisten todavía imprecisiones y ambigüedades en la definición de algunos elementos, lo que pone de relieve su carácter provisional y subraya la necesidad de continuar los esfuerzos de concreción y precisión conceptual. No obstante, el grado de elaboración alcanzado permite ya entrever su potencial interés para una mejor comprensión de los mecanismos de influencia educativa que actúan en, o se manifestan a través de, la interacción entre los diversos participantes en una actividad escolar o no escolar. Y lo que es más importante, permite mostrar que es factible, además de potencialmente interesante, Illevar a cabo un análisis de los mecanismos de influencia educativa en los términos teóricos establecidos y respetando las exigencias metodológicas apuntadas.

Dos partes diferenciadas constituyen este apartado. La primera está dedicada a presentar, definir e ilustrar las diferentes unidades que intervienen en los análisis. La segunda muestra con cierto detalle cómo pueden utilizarse estas unidades para llevar a cabo los dos tipos de análisis; es decir, cómo pueden utilizarse para analizar la evolución de las actuaciones de los participantes a lo largo de las SD/SAC y para analizar los significados que son objeto de negociación y modificación en el transcurso de las mismas. En ambos casos, utilizaremos ejemplos extraídos de las investigaciones presentadas en el apartado anterior.

\section{Las unidades de análisis}

La Secuencia Didáctica (SD), o en su caso la Secuencia de Actividad Conjunta (SAC), no es solamente la unidad básica de recogida de datos, sino también la unidad básica de análisis e interpretación. Las investigaciones que configuran el proyecto han sido diseñadas de tal manera que disponemos de registros de SD/SAC completas. La tarea consiste en analizar cómo se va articulando lo que dicen y hacen el profesor y los alumnos, o la madre y su hijo/a, en el transcurso de una SD/SAC determinada con el fin de identificar algunos mecanismos responsables de la influencia educativa que se ejerce en el transcurso de la misma. Más concretamente, lo que se pretende es captar cómo se produce, cuando se produce, el doble proceso de cesión y traspaso progresivos del control y la responsabilidad y de construcción progresiva de significados compartidos.

Para llevar a cabo esta tarea, es absoluta- 
mente necesario conservar la dimensión temporal y centrar el análisis en la evolución de la actividad conjunta en el transcurso de la $\mathrm{SD} / \mathrm{SAC}$. La SD/SAC en su globalidad y en su evolución es pues la unidad fundamental de análisis e interpretación en todas las investigaciones del proyecto. Todos los análisis que se lleven a término deben ser ubicados en el marco más amplio de la SD/SAC; es decir, deben situar inequívocamente los datos a los que se refieren en el momento o momentos de la SD/SAC a los que corresponden.

$\mathrm{El}$ propio diseño de las investigaciones determina un segundo tipo de unidades de análisis, de amplitud menor que las SD/SAC, que no plantean tampoco ningún problema de identificación. Son las Sesiones (S) de trabajo que conforman las $\mathrm{SD} / \mathrm{SAC}$ registradas. $\mathrm{Pe}$ se a su carácter un tanto inducido, o incluso impuesto según los casos, es útil considerar esta unidad de análisis de amplitud intermedia. En efecto, al inicio de una nueva sesión es necesario retomar la actividad conjunta allí donde se dejó en la sesión anterior y, en este sentido, la parcelación de una SD/SAC en varias sesiones fuerza a explicitar los procedimientos mediante los cuales los participantes aseguran la continuidad y se ponen de acuerdo sobre el camino recorrido, sobre los significados ya compartidos y sobre la experiencia previa que les ha permitido construir dichos significados compartidos.

Lo que hacen el profesor y los alumnos -o lo que hacen la madre y su hija - durante una de estas sesiones puede ser muy diverso. Por ejemplo, en una situación de lectura en clase, tiene poco sentido analizar la sesión como si fuera una sola unidad, ya que la actividad conjunta de los alumnos y del profesor va experimentando modificaciones sucesivas. Así, la forma que adopta la actividad conjunta cuando un alumno resume lo leído el día anterior mientras los otros escuchan y ocasionalmente formulan comentarios es distinta, por ejemplo, a la forma que adopta dicha actividad conjunta cuando los alumnos, uno tras otro y a instancias del profesor, van leyendo un párrafo del texto.

Parece pues razonable tratar de distinguir, a efectos de descripción y análisis de la acti- vidad conjunta de los participantes, unidades de nivel inferior a la sesión que, tomadas en su conjunto, configuran la sesión como tal. En nuestra propuesta, estas unidades se denominan Segmentos de Interactividad (SI) o segmentos de actividad conjunta. Los SI que presentan un cierto paralelismo con los segmentos de actividad (activity segments) utilizados por Stodolsky (1991), a partir de las propuestas de Barker, Gump y otros autores representativos de la psicología ecológica, para analizar las actividades que tienen lugar en el aula - se caracterizan por responder a una determinada estructura de participación (Erickson, 1982), que regula, en una situación de actividad conjunta, «los derechos y obligaciones de los participantes con respecto a quién puede decir [o hacer, añadiríamos nosotros] qué cosa, cuándo y a quién» (Cazden, 1990, p.640). Así, los SI se definen por el conjunto de actuaciones esperadas o esperables, y por lo tanto aceptadas o aceptables, de los participantes; cuando, en el transcurso de un SI determinado, los participantes exhiben comportamientos que no forman parte del conjunto de actuaciones esperadas, se producen rupturas, bloqueos o discontinuidades en la actividad conjunta y surgen llamadas de atención de los propios participantes sobre lo inadecuado de dichos comportamientos.

Desde un punto de vista metodológico, dos son los criterios esenciales que permiten identificar los SI en los que se divide una sesión: la unidad temática o de contenido (aquello de lo cual se habla o aquello de lo cual se ocupan los participantes) y el patrón de comportamientos o actuaciones dominantes. Así, ca$\mathrm{da}$ vez que se produce un cambio sustancial, y por lo tanto detectable para el observador, en uno u otro de estos dos aspectos -o en ambos-, diremos que se inicia un nuevo SI. El peso relativo de estos dos criterios para determinar cuándo finaliza un SI y comienza otro depende lógicamente de la naturaleza de la $\mathrm{SD} / \mathrm{SAC}$, y en particular de la estructura de la tarea y/o de la naturaleza del contenido en torno a los cuales se articula la SD/SAC. En realiaad, ambos criterios remiten a otros tantos aspectos de la estructura de participa- 
ción: de qué se puede hablar o qué se puede hacer (primer criterio) y quién, cómo y cuándo puede hablar o hacer algo (segundo criterio).

De este modo, un SI puede caracterizarse por el conjunto de actuaciones típicas y dominantes que exhiben las personas que participan en él y que reflejan, en último extremo, la estructura de participación subyacente. Así, en las SD con estudiantes universitarios relativas a la enseñanza y aprendizaje de un PT, hemos identificado tres tipos de S.I. a los que hemos denominado «S.I. de aportación de información», «S.I. de práctica» $y$ «S.I. de ejecución de rutinas» respectivamente. Cada SI se caracteriza por unos patrones específicos de actuaciones conjuntas permitidas y esperadas que los definen y que son propias de la situación de enseñanza y aprendizaje analizada. En el caso, por ejemplo, de los SI de aportación de información estos patrones de actuaciones conjuntas pueden definirse como sigue: Tipos de actuación y patrones característicos de
los SI de aportación de información (las actua-
ciones situadas en la misma línea son simultá-
neas; las actuaciones situadas en líneas distin-
tas son sucesivas)

Tipos de actuación del profesor

$\begin{array}{ll}\text { Explicación } & / / \\ \text { Directivas } & / /\end{array}$

Verificación

Preguntas

Respuesta/reacción

Nótese que los patrones definen actuaciones interconectadas del profesor y de los alumnos que son específicas de la situación concreta de enseñanza y aprendizaje. Así, por ejemplo, el patrón «explicación // seguimiento» implica, por parte del profesor, la simulación en la pizarra, apoyándose en dibujos y gestos, de la realización de determinadas acciones o procedimientos con el ordenador y el PT y de los efectos de las mismas; y por parte de los alumnos, la realización en paralelo de las acciones o procedimientos simulados por el profesor y la observación en sus pantallas de los elementos implicados y los efectos reales obtenidos. En este patrón el profesor emplea sistemáticamente al menos dos tipos de elementos como apoyo en la actuación de explicación: elementos del contexto extralingǘstico inmediato - como los dibujos en la pizarra o las pantallas de los ordenadores de los alumnos-y elementos de la actividad propia y de los alumnos - como sus propias manipulaciones simuladas del ordenador y las manipulaciones reales que los alumnos realizan en paralelo sobre sus ordenadores-, articulándose ambos tipos de elementos mediante un discurso que adopta un aspecto muy característico (descripción de acciones y elementos implicados en lo que se está realizando, especificación de objetivos y subobjetivos de la acción conjunta, anticipación de resultados o efectos de las acciones,...). En cuanto a los alumnos, realizan un seguimiento activo, en un marco altamente pautado y controlado, que les permite, por un lado, realizar efectivamente las diferentes acciones y procedimientos nuevos que se introducen en el SI aún sin necesidad de comprender completamente todos los aspectos implicados, y por otro detectar de forma inmediata anomalías o incomprensiones a partir de la no coincidencia entre los efectos o resultados anticipados por el profesor y los que se producen realmente. $^{6}$

Un último aspecto de importancia en relación a los SI es que, además de cumplir la función, como hemos indicado, de definir qué puede/debe estar haciendo/diciendo cada uno de los participantes en cada momento de la SD, implican igualmente funciones instruccionales específicas. Por ejemplo, respecto al nivel de control sobre la actividad conjunta que tienen los participantes, en los SI de aportación de información el control es ejercido fundamentalmente por el profesor, mientras que la situación se invierte en los SI de práctica. Esto hace que los distin- 
tos tipos de SI identificados tengan un significado teórico relevante desde la perspectiva de los mecanismos de influencia educativa, siendo especialmente importantes las variaciones relativas a la articulación, distribución y organización interna de los mismos conforme avanzan las SD.

Por supuesto, en la medida en que la estructura de participación y las actuaciones típicas de los participantes varían en función, entre otros factores, de la naturaleza de la tarea y/o del contenido de las SD/SAC, los tipos y características de los SI son también distintos en cada una de las situaciones de observación incluidas en el proyecto. Así, en algunas SD relativas a la enseñanza y el aprendizaje de la numeración y de algunas operaciones elementales de cálculo ${ }^{7}$, hemos podido identificar cuatro tipos distintos de SI denominados, respectivamente, «SI de preparación y organización del juego», «SI de partida», «SI de valoración de resultados» $y$ «SI de recapitulación». A título de ejemplo, presentamos las actuaciones de los participantes que caracterizan el SI de partida.

\section{Actuaciones características de los SI de partida}

Actuaciones predominantes de la maestra

Atribución y/o control explícito -verbal o no verbal - del turno de tirada al niño al que le corresponde tirar

Seguimiento explícito de la tirada acompañado eventualmente de un recordatorio de las reglas del juego

Identificación y corrección de errores

Identificación de errores sin corrección

Petición a los alumnos que no tiran de que identifiquen y/o corrijan posibles errores cometidos por el alumno que tira o de que ejerzan un control sobre cualquier aspecto de la partida

Actuaciones predominantes de los alumnos que tiran

Asunción espontánea del turno cuando le corresponde

Asunción del turno tras el requerimiento de la maestra

Asunción del turno a petición de otros alumnos

Ejecución de los pasos de la tirada

Anticipación explícita y espontánea de algunos pasos de la tirada o del resultado de la misma

Identificación y/o corrección espontánea de los errores cometidos

Corrección del error a petición de la maestra
Corrección del error a petición de otro alumno que no tira

Actuaciones predominantes de los alumnos que no tiran

Atribución y/o control explícito -verbal o no verbal - espontáneo del turno de tirada al niño al que le corresponde tirar

Intervenciones espontáneas dirigidas al control, supervisión y/o anticipación de la tirada, o de los resultados de la tirada, realizada por el alumno que tira

Identificación y/o corrección espontánea de los errores cometidos por el alumno que tira

Identificación y/o corrección, a requerimiento de la maestra, de los errores cometidos por el alumno que tira

Como puede comprobarse, estas categorías intentan recoger los aspectos más sobresalientes de la organización de la actividad conjun. ta, es decir, de la articulación de las actuaciones de la maestra y de los niños durante el desarrollo del juego. En efecto, si bien las categorías de actuaciones se presentan en este caso por separado para los distintos participantes - maestra, alumnos que tiran, alumnos que no tiran-, en realidad están estrechamente interrelacionadas, de tal manera que el interés del análisis reside más bien en la búsqueda de posibles patrones de actuación conjunta y en su evolución que en la consideración de cada una de ellas por separado. Por ejemplo, en el caso de los SI de partida puede ser interesante indagar si aparecen distintos patrones de actuación conjunta en lo que concierne a la producción, identificación y corrección de errores (un patrón posible: producción de un error por el alumno que tira / identificación y corrección de este error por la maestra; otro: producción de un error por el alumno que tira / identificación del error por la maestra / corrección del error por el alumno; etc.) y si estos patrones evolucionan de manera significativa a lo largo de la SD.

Nótese, asimismo, que las categorías de actuaciones han sido definidas de tal manera que, tomadas en conjunto, recubren los principales momentos o fases de la realización de la tarea. Siguiendo con el ejemplo de los SI de partida, encontramos categorías que remiten a los tres momentos o fases cruciales del 


\section{8}

juego: el turno de tirada («atribución o control explícito - verbal o no verbal- del turno de tirada al niño al que le corresponde tirar»; «asunción espontánea del turno cuando le corresponde»; etc.), la realización de la tirada («ejecución de los pasos de la tirada»; «intervenciones espontáneas dirigidas al control, supervisión y/o anticipación de la tira$\mathrm{da}$, o de los resultados de la tirada, realizada por el alumno que tira», etc.) y producción, identificación y corrección de errores («identificación y corrección de errores»; «corrección del error a petición de la maestra»; etc.).

El carácter específico de la estructura de participación, de las categorías y patrones de actuación conjunta, y en consecuencia de los SI, vuelve a ponerse de mánifiesto si nos fijamos en las SAC relativas al mundo de los gnomos. En este caso, hemos podido identificar tres tipos de SI denominados, respectivamente, «SI de delimitación del escenario fisico y simbólico», «SI de representación de acontecimientos» y «SI de profundización en características del mundo gnomo $y / o$ bumanos. A título de ilustración, las actuaciones que caracterizan el SI de representación de acontecimientos son las siguientes:

Actuaciones características de la madre y del ni. ñola en los SI de representación de acontecimientos

Formula espontáneamente una propuesta de representación de acontecimientos

Hace un requerimiento al otro participante para que formule una propuesta de representación de acontecimientos

Tras el requerimiento del otro participante, formula una propuesta de representación de acontecimientos

Formula una propuesta de representación de acontecimientos y requiere al otro participante so. bre la misma

Formula espontáneamente comentarios sobre la propuesta de representación de acontecimientos realizada por el otro participante

Tras el requerimiento del otro participante, formula comentarios sobre la propuesta de representa. ción de acontecimientos realizada por el otro

Formula espontáneamente comentarios sobre la distribución de roles y/o sobre otros aspectos relativos a la organización del acontecimiento representado

Hace un requerimiento al otro participante sobre la distribución de roles y/o sobre otros aspec- tos relativos a la organización del acontecimiento representado

Tras el requerimiento del otro participante, formula comentarios sobre la distribución de roles y/o sobre otros aspectos relativos a la organización del acontecimiento representado

Adopta roles con independencia de los roles asumidos por el otro participante y/o lleva a cabo la representación al margen del acontecimiento representado por el otro

Actuaciones propias de representación del acontecimiento (desplaza los elementos, «hace hablar» a los personajes, describe lo que hacen o dicen los personajes, etc.)

Da por finalizada la representación del acontecimiento

$\mathrm{Al}$ igual que en las otras dos situaciones comentadas, la definición y selección de las actuaciones de los participantes que sirven para caracterizar los diferentes tipos de SI encuentran su justificación última en el marco teórico del proyecto y en los objetivos del mismo. Así, la importancia otorgada a las interrelaciones existentes entre lo que hacen y dicen los participantes se traduce, por ejemplo, en el hecho de que las actuaciones, tal como han sido definidas, implican a menudo a ambos participantes («formula una propuesta de representación de acontecimientos y requiere al otro participante sobre la misma»; «hace un requerimiento al otro participante sobre el tema de la profundización»; etc.). Y también en el hecho de que, tomadas en su conjunto, las categorías de actuaciones permiten identificar posibles patrones de actuación conjunta (un patrón posible en los SI de representación de acontecimientos: la madre hace un requerimiento al niño para que formule una propuesta de representación de acontecimientos / el niño formula la propuesta / la madre formula comentarios sobre la propuesta del niño; otro: el niño formula espontáneamente una propuesta de representación de acontecimientos / la madre hace un requerimiento al niño sobre la distribución de roles en la representación del acontecimiento propuesto; etc.) y analizar su evolución a lo largo de las SAC.

Del mismo modo, y como consecuencia del interés por comprender cómo se produce si es que se produce- la cesión y traspaso 


\section{9}

progresivos de la responsabilidad y del control, se intenta que las actuaciones en su conjunto recubran diferentes dimensiones relativas a la participación de los miembros de la pareja en el desarrollo de la SAC. Concretamente, las actuaciones tienen en cuenta el grado de iniciativa de los participantes (participación espontánea), el grado de interconexión de sus aportaciones (hasta qué punto un participante está pendiente y considera lo que dice y/o hace el otro) y el grado en que se potencia la participación del otro (invitaciones al otro a participar y adecuación de la participación a las invitaciones formuladas por el otro). Como puede comprobarse mediante una lectura atenta de la formulación de las actuaciones, estas tres dimensiones subyacen a las categorías utilizadas para caracterizar los tres tipos de SI.

El procedimiento seguido para la identificación de los SI es similar en todos los casos. Tras visionar varias veces los registros de la $\mathrm{SD} / \mathrm{SAC}$-o leer varias veces las transcripciones, cuando los registros disponibles son únicamente audio- se lleva a cabo una primera segmentación intuitiva. Seguidamente, se revisan todos y cada uno de los SI identificados en esta primera aproximación con la ayuda de los criterios antes descritos (unidad temática o de contenido y presencia de un patrón de comportamientos o actuaciones dominantes) y se introducen, si la revisión así lo aconseja, las correcciones oportunas. En caso de dudas sobre cuándo termina un SI y comienza otro, se definen criterios opera'cionales complementarios y, si pese a todo persisten las dudas, se utiliza un procedimiento de toma de decisiones por consenso entre jueces.

El análisis detallado de los tipos y características de los SI que se suceden en el trans. curso de la SD/SAC es susceptible de proporcionarnos una visión bastante ajustada de la estructura de la actividad conjunta desarrollada por los participantes y de su evolución. En este sentido, los SI definen, por así decirlo, el contexto de actividad en el cual $-\mathrm{y}$, al menos en parte, gracias al cual- los participantes pueden actualizar, negociar, modificar y eventualmente compartir sistemas de significados sobre el contenido o tarea que les ocupa. Sin embargo, el carácter excesivamente global de los SI hace que no sean unas unidades de análisis adecuadas para profundizar en el proceso de construcción de significados que acontece supuestamente en el transcurso de las SD/SAC. Para indagar si este proceso se lleva efectivamente a cabo $-y$, en el caso de que así sea, para indagar cómo se lleva a cabo - se requiere una unidad de análisis mucho más fina, de naturaleza esencialmente semiótica y cuyas relaciones con el contexto de la actividad conjunta reflejada en los SI sean fáciles de establecer.

Hemos definido los mensajes como la unidad mínima más apropiada. Entendemos por mensaje la expresión, a cargo de uno de los participantes en la actividad conjunta, de una unidad de información que tiene sentido en sí misma y que, por lo tanto, no puede des. componerse en unidades más elementales sin perder el significado que transmite, sin perder su valor de información y, consecuentemente, sin perder su potencialidad comunicativa en el contexto de la actividad en que ha sido producida.

Conviene subrayar que, de acuerdo con esta definición, los mensajes son al mismo tiempo unas unidades elementales de significado y unas unidades básicas de conducta comunicativa. Esta doble caracterización determina de forma decisiva el tipo de análisis de los significados que es posible llevar a cabo utilizando los mensajes como punto de partida. En efecto, al elegir los mensajes como unidad de análisis, estamos optando por estudiar los significados en el contexto de la actividad comunicativa; en otros términos, estamos optando por centrar el análisis en los significados que comunican, interpretan y negocian los participantes mediante su actividad dis. cursiva. Esto implica dejar al margen, o al menos en un segundo plano, algunos aspectos del significado que han sido tradicionalmente objeto de atención prioritaria en la semántica lingüística - los aspectos que Lyons (1983) incluye bajo el rótulo de contenido proposicional y significado de las oraciones-y orienta, en contrapartida, hacia una aproximación pragmática al estudio del significado. 
Algunas precisiones pueden ayudarnos a perfilar la definición propuesta para los mensajes. En primer lugar, los mensajes incluyen siempre un ingrediente no verbal formado por los componentes prosódicos (entonación, pausas, etc.) y paralingüísticos (miradas, señalamientos, etc.) que acompañan las producciones lingüísticas. De ahí que su identificación, es decir, la decisión de lo que es un mensaje de acuerdo con los criterios establecidos por la definición (unidades mínimas de información con potencialidad comunicativa en el contexto de la actividad en que aparecen), exija tener en cuenta tanto los componentes verbales como las claves prosódicas y paralingüísticas de la actividad discursiva. En segundo lugar, aunque el canal utilizado con mayor frecuencia en la actividad conjunta sea el verbal, es obvio que los participantes pueden comunicarse entre sí y transmitirse significados utilizando otros canales. Es lo que sucede, por ejemplo, cuando uno de los participantes en la actividad conjunta hace un gesto de afirmación o negación (con la cabe$z a$, con los dedos, etc.) en respuesta a una pregunta formulada por otro participante; o aún, cuando uno de los participantes, mediante un gesto de señalamiento o indicación (con la mirada, con el dedo, con un movimiento de la cabeza, etc.), llama la atención de otro participante sobre un elemento o aspecto de la situación. En tercer lugar, los mensajes verbales, o mejor dicho, los componentes verbales de los mensajes, admiten múltiples variantes desde el punto de vista gramatical y formal. Un mensaje puede estar formado por una sola palabra o por varias oraciones. En otros términos, los mensajes no se definen por la estructura formal de los enunciados, sino por su valor informativo y comunicativo. Por último, en las situaciones en las que la actividad discursiva de los participantes adopta la forma de una sucesión de intercambios comunicativos - como ocurre, por ejemplo, en buena medida en las SAC de los gnomos y en algunos SI de las SD de enseñanza y aprendizaje de la numeración y de enseñanza y aprendizaje de un procesador de textos-, conviene diferenciar claramente entre mensajes y turnos de los participantes. En efec- to, cada participante puede «llenar» su turno con uno o varios mensajes, es decir, con una o varias unidades de información que tienen sentido en sí mismas.

Se incluyen a continuación algunos ejemplos de mensajes, extraídos de las tres situaciones de observación descritas anteriormente, con el fin de ilustrar esta casuística.

SD de enseñanza y aprendizaje de un procesador de textos.

Grupo de Universitarios sin conocimientos previos. $1^{a}$ Sesión. SI $n^{\circ} 1$ : aportación de información. Todos los mensajes son producidos por el profesor. Los corchetes señalan el principio y el final de los mensajes. Los componentes prosódicos y paralingüísticos de los mensajes figuran entre paréntesis. Los puntos suspensivos indican una pausa en la emisión verbal. [en este caso lo primero quie le vamos a decir es que nos muestre el contenido que hay dentro del disco]

- [para que nos muestre el contenido que hay dentro del disco lo que haríamos es desplazaríamos la flecha encima ... del dibujo del disco ..., eh?] (señala en el dibujo de la pizarra) [desplazaríamos] (gesto de desplazar)

[nos pondríamos encima] (dibuja la flecha sobre el ícono del disco en la pizarra)

[y si os fijáis el ... la cajita tiene una tecla] [un interruptor]

[una vez que estamos encima del disco haciendo un doble clic

[un doble clic significa dar dos veces al botoncito] (gesto con los dedos de doble clic)

haciendo un doble clic sobre el botón se va a abrir el contenido del disco y nos va a mostrar lo que hay dentro]

$S D$ de enseñanza y aprendizaje de la numeración $y$ de algunas operaciones elementales de cálculo (juego «salta»).

Primero de preescolar (P4). $1^{\text {a }}$ Sesión. SI $n^{\circ}$ 1: preparación y organización del juego. $\mathrm{M}$ : Maestra. Ja: Alumno. Los corchetes señalan el principio y el final de los mensajes. Los componentes prosódicos y paralinguísticos de los mensajes figuran entre paréntesis. Los puntos suspensivos indican una pausa en la emisión verbal.

M: [també tindreu un dau entre dos]

M: [i tindreu una fitxa cadascú $ं e h ?]$

$M$ : [o sigui, que de daus en posem tres]

$\mathrm{M}$ : [a veure, per exemple, el Javi tindrà la fitxa de color .... (muestra a Javi la ficha de co- 
lor rojo; entonación inquisitiva)

Ja: [vermell]

M: [vermell] (da la ficha de color rojo a Javi)

$S A C$ relativa al mundo ficticio de los gnomos. SAC Nora $(5 ; 6)$.

M: Madre. N: Nora. Los corchetes señalan el principio y el final de los mensajes - verbales y no verbales. Los componentes prosódicos y paralingüísticos de los mensajes figuran entre paréntesis. Los puntos suspensivos indican una pausa en la emisión verbal.

$4^{\text {a }}$ Sesión. SI ${ }^{\circ}$ 1: delimitación del escenario físico y simbólico

\section{M: [¿cuál es la gnoma?]}

M: [¿es ésta?] (coge una gnoma y se la mues. tra a N)

$\mathrm{N}$ : [gesto de negación con la cabeza]

$\mathrm{M}$ : [¿es ésta?] (coge otra gnoma y se la mues. tra a N)

$\mathrm{N}$ : [gesto de negación con la cabeza]

$\mathrm{M}$ : [¿es ésta?] (coge una tercera gnoma y se la muestra a $\mathrm{N}$ )

$\mathrm{N}$ : [gesto de afirmación con la cabeza]

$6^{a}$ Sesión. SI $n^{0}$ 2: profundización en características del mundo gnomo y/o humano

M: [tú Nora ... ¿qué pasa cuando ... cuando una persona se muere?]

M: [¿qué le pasa ... a ver ... ¿ tú qué crees que le pasa?]

$\mathrm{N}$ : [no lo sé]

$M:$ [¿no lo sabes?]

$\mathrm{N}:[\dot{\mathrm{j} y}$ tú?]

M: [bueno ... exactamente tampoco lo sé]

$\mathrm{M}$ : [solamente sé que se mueren]

M: [pero me parece que no se convierten así ... en árbol]

M: [esto solamente lo hacen los gnomos]

$M$ : [pero se tienen que morir porque no pueden vivir toda la vida]

$\mathrm{N}$ : [claro]

M: [una flor sale ... se abre ... y al cabo de unos días ... ¿qué le pasa?]

$\mathrm{N}:$ [claro]

$\mathrm{M}$ : [se muere ... ¿no?]

$\mathrm{N}$ : [mira a M y asiente con la cabeza]

Como puede intuirse a partir de estos ejemplos, la identificación de los mensajes es una tarea costosa, difícil y delicada que exige integrar informaciones de naturaleza diversa. En la medida en que los mensajes se definen como unidades elementales de información interpretables en el contexto de la actividad en que aparecen, las transcripciones de los registros, por muy precisas y detalladas que sean, no bastan en ocasiones para su identificación y segmentación, siendo necesario recurrir con frecuencia a los registros audio y video originales para valorar los índices contextuales (entonación, pausas, énfasis, gestos, movimientos, miradas, etc.). Por otra parte, y habida cuenta de la compleja casuística a la que hay que hacer frente, es imprescindible adoptar criterios operacionales para resolver las dudas y llevar un cuidadoso registro de las mismos con el fin de mantener la coherencia en la toma de decisiones. Todo ello hace que, para identificar y segmentar los mensajes, sea altamente recomendable - más aún si cabe que en el caso de la identificación de los SI - utilizar el procedimiento de consenso entre jueces a partir de unos criterios previos.

Las $S D / S A C$, las Sesiones, los SI y los mensajes son las cuatro unidades básicas de nuestro modelo de análisis. Como hemos visto, son unidades de naturaleza distinta. Su amplitud y grado de finura varía desde el carácter global y «macro» de las SD/SAC hasta el carácter elemental y «micro» de los mensajes. Todas han sido pensadas, definidas o redefinidas con el fin de jugar un papel determinado en el análisis y la interpretación de las observaciones (las SD/SAC, garantes de la dimensión temporal y referentes últimos de las interpretaciones; las Sesiones, susceptibles de mostrar cómo los participantes aseguran la continuidad en la actividad conjunta y en la construcción de significados compartidos; los SI, reflejo de las formas de organización de la actividad conjunta e instrumento para analizar sus características y evolución; los mensajes, unidades elementales de información y comunicación que abren el camino al análisis de la construcción de significados compartidos en la actividad conjunta). Y, lo que es más importante, ocupan niveles distintos en una especie de jerarquía, de tal manera que las situadas en un nivel superior incluyen las situadas en un nivel inferior (las $\mathrm{SD} / \mathrm{SAC}$ están formadas por Sesiones; las Sesiones por SI; y los SI por mensajes), facilitando así las conexiones entre los análisis correspondientes $\mathrm{y}$, sobre todo, la integración 
de los resultados y de las interpretaciones respectivas.

Señalemos aún, para terminar este apartado, que, junto a las cuatro unidades básicas descritas, los análisis de los registros realizados hasta el momento nos han permitido establecer otros dos tipos de unidades derivadas que encierran un indudable interés. En primer lugar, en las SD relativas al aprendizaje y la enseñanza de un procesador de textos, hemos podido constatar la existencia de una Configuración de Segmentos de Interactividad (CSI) que se repite con cierta regularidad y sistematicidad. En el apartado siguiente veremos cómo esta CSI, integrada por un SI de aportación de información y un SI de práctica, parece tener una función instruccional muy definida y juega, según nuestra interpretación, un papel destacado en la cesión y el traspaso progresivos de la responsabilidad y del control que lleva a cabo el profesor a medida que avanzan las SD.

En segundo lugar una serie de consideraciones de orden teórico y metodológico aconsejan establecer una unidad de análisis intermedia entre los SI y los mensajes para la que proponemos la denominación de Configuraciones de Mensajes (CM), ya que se trata de una unidad derivada a partir de éstos. Las $\mathrm{CM}$ son, en nuestra concepción, agrupaciones de mensajes que, por su organización y estructuración, transmiten significados que no pueden reducirse a la suma de los significados transmitidos por cada uno de los mensajes que las integran. Las CM pueden adoptar probablemente formas distintas según el contex to de la actividad conjunta (intercambios instruccionales del tipo IRF o similares, estructuras conversacionales diversas, grupos de mensajes con una fuerte coherencia temática, tópicos, etc.) y la búsqueda de criterios para identificarlas es sin duda uno de los retos más importantes con los que se enfrenta el análisis de la construcción de significados compartidos.

\section{Los niveles de análisis}

Nuestra aproximación a los datos establece dos niveles de análisis: el primero dirige la atención a las actuaciones de los participantes, sus interrelaciones y su evolución a lo largo de las SD/SAC, toma los SI como unidad básica de trabajo y tiene como objetivo fundamental aportar elementos de respuesta a las cuestiones relativas a la cesión y traspaso progresivos del control y la responsabilidad; el segundo centra los esfuerzos en los significados que actualizan los participantes mediante su actividad discursiva, utiliza para ello los mensajes como unidad básica de indagación y responde al propósito de obtener información sobre cómo se produce, cuando se produce, la construcción progresiva de sistemas de significados compartidos en el transcurso de las SD/SAC. Ambos, recordémoslo una vez más, son complementarios, de modo que sus resultados respectivos se apoyan y se enriquecen mútuamente en aras de una interpretación integrada.

\section{El primer nivel de análisis: las formas de organización de la actividad conjunta y la estructura de la interactividad}

El procedimiento de análisis comienza con la identificación de los Segmentos de Interactividad (SI) utilizando el procedimiento descrito en el apartado anterior. Esto permite establecer la estructura de la interactividad, es decir, las distintas formas de organización de la actividad conjunta de los participantes en el transcurso de las SD/SAC. Esta estructura puede representarse gráficamente dando lugar a lo que hemos denominado el mapa de interactividad de las SD/SAC. Los mapas de interactividad ofrecen una visión de conjun. to de las distintas formas de organización de la actividad conjunta que aparecen en las $\mathrm{SD} / \mathrm{SAC}$, de su distribución temporal y de su evolución en el transcurso de las sucesivas sesiones que las conforman. La figura 1 muestra el mapa de interactividad de la SD de enseñanza y aprendizaje de un procesador de textos observada en el grupo de alumnos universitarios con conocimientos previos.

La escala temporal, que aparece en la parte izquierda de las figuras, está dividida en intérvalos de cinco minutos. Cada una de las sesiones - cuatro en estas $\mathrm{SD}$-, de $120 \mathrm{mi}$ - 
Figura 1

Mapa de interactividad de la SD observada en el grupo de alumnos con conocimientos previos

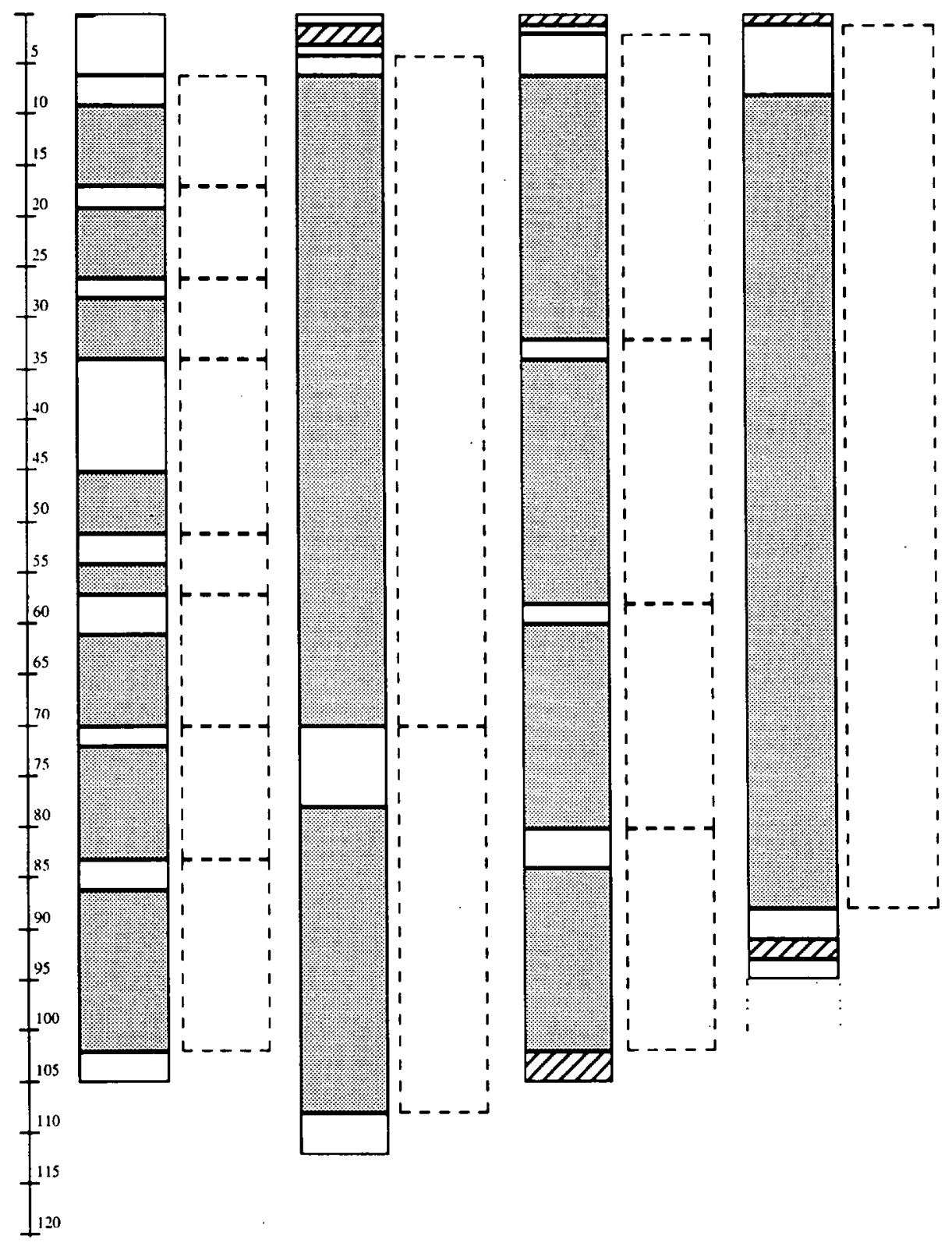

nutos de duración cuando se agota el tiempo previsto, está representada mediante dos columnas divididas en rectángulos, que indican diferentes formas de organización de la actividad conjunta y cuyo tamaño refleja las du- raciones respectivas redondeadas a minutos. Los rectángulos de la columna de la izquier. $\mathrm{da}$, hechos con trazo contínuo, representan los distintos tipos de SI identificados - según la trama: en blanco, los SI de aportación de 
información; con puntos, los SI de práctica; con trazos inclinados, los SI de ejecución de rutinas-y su duración temporal —según el tamaño. Los rectángulos de la columna de la derecha, hechos con trazo discontínuo, representan las Configuraciones de SI identificadas -denominadas en este caso Unidades Instruccionales-, su duración temporal y los SI que las integran.

Así, el mapa de interactividad que aparece en la figura 1 indica que la primera sesión de la SD comienza con un SI de aportación de información que dura unos seis minutos aproximadamente, seguido de otro SI del mismo tipo de unos dos minutos; a éste, le sigue un SI de práctica de aproximadamente ocho minutos; después, otro de aportación de información de alrededor de dos minutos; a continuación, otro de práctica de aproximadamente siete minutos; y así sucesivamente hasta el final de la sesión. Del mismo modo, la columna de la derecha correspondiente a la primera sesión muestra que el primer SI de aportación de información no se incluye en ninguna Unidad Instruccional (UI), iniciándose la primera de estas unidades con el segundo SI de la sesión. Globalmente, las dos columnas correspondientes a la primera sesión indican que, en el transcurso de la misma, se han identificado dieciocho SI, diez de los cuales son de aportación de información y ocho de práctica, que no se ha encontrado ningún SI de ejecución de rutinas y que dieciseis de los dieciocho SI identificados se integran en ocho UI.

Los mapas de interactividad ofrecen una descripción visual inmediata de la evolución de las formas de organización de la actividad conjunta - concretadas en los distintos tipos de SI- en el transcurso de las SD/SAC. Así, una simple «lectura» de la figura 1 nos informa de los siguientes extremos: el número de SI por sesión disminuye considerablemente en el transcurso de la SD, pasando de dieciocho en la primera a seis en la última; los SI de ejecución de rutinas no aparecen hasta la segunda sesión y se presentan siempre al inicio y/o al final de las sesiones; la duración de los SI de práctica se incrementa progresivamente en las sesiones sucesivas, mientras que en los SI de aportación de información no se detecta esta tendencia; también disminuyen las UI por sesión, que pasan de ocho en la primera a una en la última; la duración de las UI se incrementa también progresivamente, hasta tal punto que en la última sesión una sola UI ocupa la mayor parte del tiempo.

Estos cambios detectados en la duración y la estructura interna de las formas de organización de la actividad conjunta pueden ser objeto, seguidamente, de análisis más específicos dirigidos a precisar y valorar su alcance. Sin entrar en un comentario pormenorizado de estos análisis, lo que nos interesa subrayar aquí es que el procedimiento utilizado para definir e identificar los SI -y en especial la propuesta de contemplarlos desde la perspectiva de la cesión y el traspaso progresivos de la responsabilidad y del controlpermite interpretar las tendencias detectadas en los mapas de interactividad y en los análisis específicos subsiguientes como indicadores empíricos de los procesos de influencia educativa que tienen lugar en las SD/SAC. Así, como se recordará, en el caso de las SD relativas al procesador de textos señalábamos que el control de los participantes sobre la actividad conjunta es sustancialmente distinto en los SI de aportación de información y en los SI de práctica. Mientras en los primeros el control es ejercido fundamentalmente por el profesor, los alumnos lo asumen en buena medida en los segundos, aunque el profesor siga ejerciendo, en la mayoría de los casos, una estrecha vigilancia sobre el desarrollo de la actividad. Si se acepta esta caracterización de los SI, entonces las tendencias detectadas en los mapas de interactividad y en los análisis subsiguientes pueden ser interpretadas sobre todo cuando se las considera de manera integrada - en términos de cesión y traspaso progresivos del control y la responsabilidad.

En efecto, remitiéndonos de nuevo a la figura 1 , son numerosos los indicadores que convergen en apoyo de esta interpretación. En la primera sesión, el profesor ejerce un fuerte control sobre el desarrollo de la actividad conjunta: así parece indicarlo el elevado nú- 
mero de SI, la alternancia entre SI de aportación de información y SI de práctica, la duración relativamente breve de unos y otros, la existencia de varias UI cuya función parece ser la de asegurar el dominio funcional de bloques de información y de procedimientos específicos antes de presentar informaciones. y procedimientos nuevos, etc. El control ejercido por el profesor durante esta sesión se manifiesta, pues, no sólo en el peso que tienen los SI de aportación de información, sino también, como puede verse, en la estructura de la interactividad, es decir, en la manera como se suceden y se organizan los SI. El panorama cambia sustancialmente en las sesiones siguientes: disminuye el número total de SI por sesión; los SI de aportación de información siguen teniendo una duración limitada mientras que los SI de práctica ven considerablemente incrementada su duración los alumnos ejercen el control de la actividad durante más tiempo-; las UI tratan de asegurar el dominio funcional de procedimientos y de bloques de información cada vez más amplios e integrados; etc. La última sesión presenta unas características diametralmente opuestas a las de la primera: el número de SI es muy pequeño; un solo SI de práctica de gran duración ocupa la mayor parte del tiempo; hay una sola UI, cuya función parece ser precisamente la de hacer funcional esta integración de informaciones y procedimientos; etc.

En suma, todos los indicadores apuntan en la misma dirección. Al inicio de la SD, el profesor mantiene un control bastante estricto sobre la actividad, si bien crea sistemáticamente pequeños espacios -los SI de práctica - para que los alumnos asuman algunas parcelas de responsabilidad. Son espacios «pequeños» en un doble sentido: su duración es relativamente corta y las tareas que realizan los alumnos están limitadas en cuanto al número y complejidad de los procedimientos que es necesario utilizar para ejecutarlas. $\mathrm{Al}$ final de la SD, todo parece indicar que el profesor ha cedido a los alumnos gran parte del control de la actividad. Durante la mayor parte del tiempo, los alumnos realizan las tareas bajo su propia responsabilidad, aunque el profesor sigue ejerciendo un cierto control mediante las actuaciones de seguimiento de la práctica y los intercambios instruccionales que mantiene eventualmente con algunas parejas, ya sea a iniciativa propia, cuando detecta dificultades o problemas, ya sea a iniciativa de los alumnos, cuando piden informaciones complementarias o solicitan ayuda.

La descripción anterior puede inducir a pensar que la cesión y el traspaso progresivos de la responsabilidad y del control se pro. duce suavemente, sin grandes dificultades y de manera casi automática en todas, o prácticamente todas, las SD/SAC. Sería una inferencia totalmente errónea. En primer lugar, los mapas de interactividad de las dos SD que estamos comentando muestran que se trata más bien de un proceso en el que se producen con relativa frecuencia variantes, altibajos, dificultades y contratiempos. Véase, por ejemplo, cómo la tercera sesión de la SD -Figura 1- no responde a la tendencia general que hemos descrito. Los mapas de interactividad, tal como han sido construidos, permiten pues detectar tanto las tendencias generales en la evolución de las formas de organización de la actividad conjunta como los puntos o momentos de las $S D$ en que estas tendencias, por las razones que sean, no se cumplen.

En estos casos, es necesario recurrir a un análisis más fino de los diferentes tipos de actuaciones de los participantes para comprender qué ha sucedido, por qué se produce una desviación de la tendencia general, cómo los participantes enfrentan las dificultades surgidas y cómo se restablece el proceso de cesión progresiva del control y la responsabilidad. En realidad, el análisis de los diferentes tipos de actuaciones de los participantes, y en particular de su evolución en el transcurso de la SD, permite captar en todos los casos algunos aspectos de la organización de la actividad conjunta que escapan a la descripción un tanto gruesa que reflejan los mapas de interactividad y los análisis derivados de los mismos. Así, por ejemplo, las consig. nas que abren siempre los SI de práctica presentan una evolución significativa en el tran. curso de las SD: limitadas al principio a plan- 
FIGURA 2

Mapa de interactividad de la SD «salta» observada en el grupo de P4

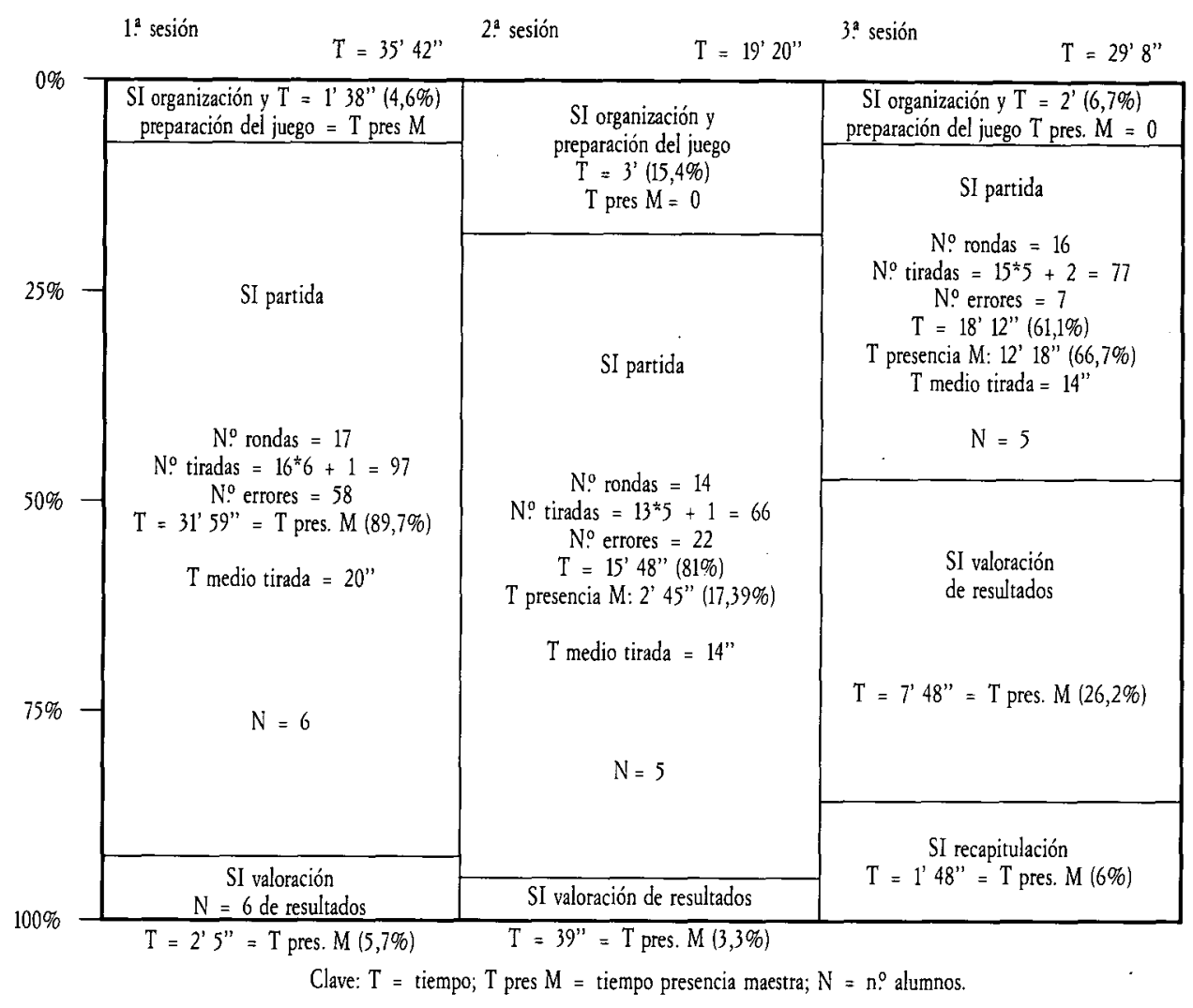

tear tareas directamente vinculadas a la utilización de la información presentada en los SI de aportación de información que les preceden, van ampliando su alcance de tal manera que obligan a integrar informaciones y procedimientos progresivamente más numerosos y complejos. Este ejemplo muestra con claridad hasta qué punto el análisis de la evolución de las actuaciones de los participantes que caracterizan los diferentes tipos de SI puede aportar informaciones complementarias sobre el proceso de cesión y traspaso progresivos del control y la responsabilidad. En efecto, $y$ en lo que concierne a la formulación de las consignas, la evolución señalada puede interpretarse, en concordancia con los otros indicadores mencionados, en el sentido de que el profesor va cediendo progresivamente a los alumnos el control de la actividad planteando tareas cada vez más amplias y más complejas.
El hecho de que en los mapas de interactividad - y en las formas de organización de la actividad conjunta que representan- podamos encontrar indicadores interpretables en términos de cesión y traspaso no asegura, por sí sólo, que los alumnos hayan asumido realmente el control y la responsabilidad cedidos por el profesor. Para estar seguros de ello, sería necesario poder demostrar que los alumnos han alcanzado efectivamente un nivel aceptable de dominio en el manejo del procesador de textos. Aunque esto es, en efecto, lo que muestran los resultados de la evaluación sumativa final realizada con los alumnos que han participado en la SD, no hay razón para suponer que haya de ser siempre necesariamente así; o para decirlo de otra manera, los indicadores de cesión y traspaso progresivos del control y la responsabilidad detectados a partir de las formas de organización de la actividad conjunta no garantizan 
FIGURA 3

Mapa de interactividad de la SAC. Nora $(5 ; 6)$

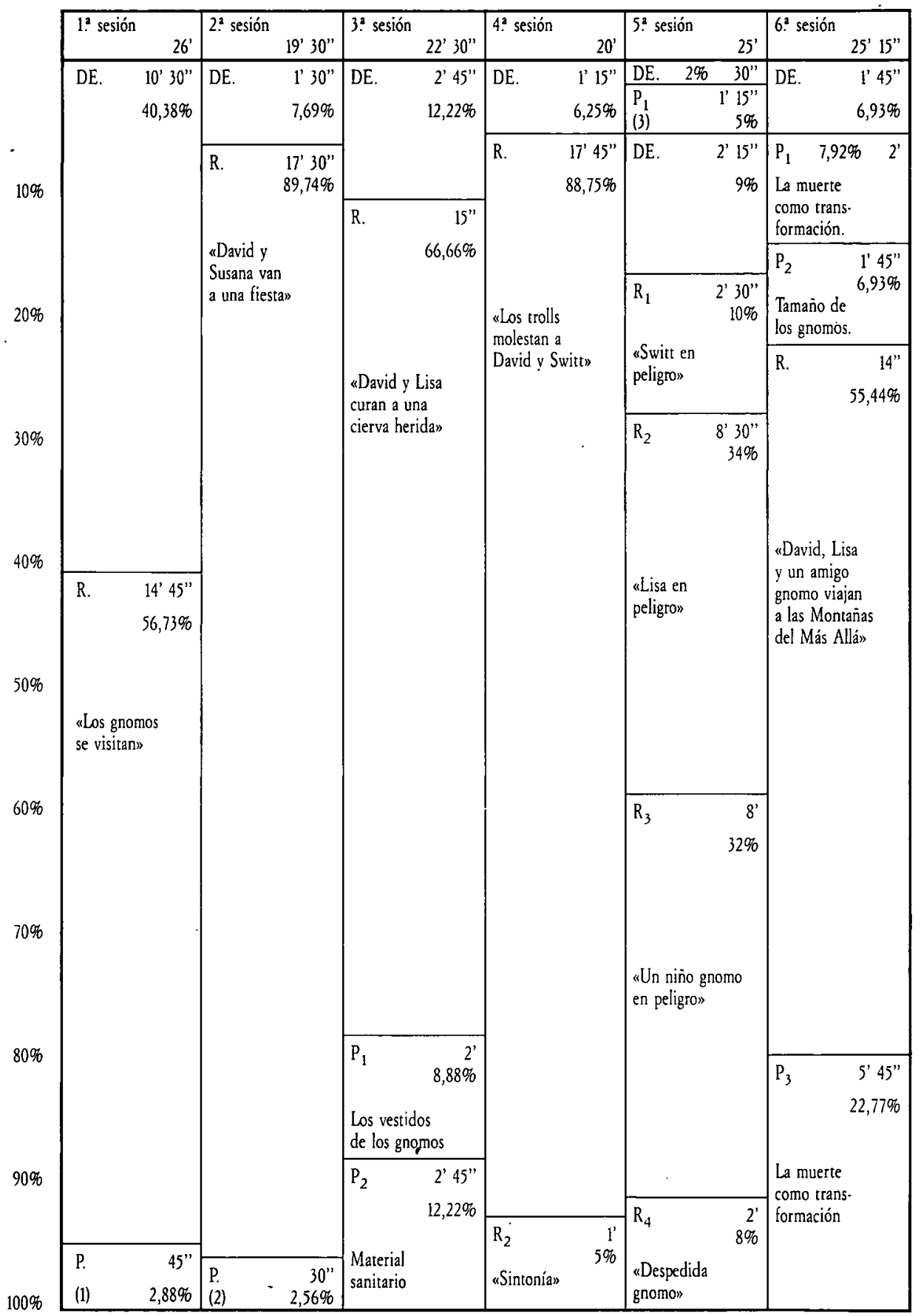

(1) Características físicas de los trolls.

(2) El nacimiento de los gnomos: los gemelos.

(3) Recursos para volver a casa cuando alguien se pierde. 


\section{8}

por sí solos que el proceso ha tenido éxito y que los alumnos han realizado los aprendizajes correspondientes implicados en dicha actividad. Son, eso sí, indicadores que apuntan en esa dirección, y que lo hacen con fuerza tanto mayor cuanto mayor es su convergencia, pero que en cualquier caso necesitan completarse con otros tipos de análisis.

Los mapas de interactividad no siempre permiten una lectura tan inmediata, $y$ tan directamente interpretable en términos de cesión y traspaso progresivos del control y la responsabilidad, como en el caso de la figura 1. A veces, simplemente porque este proceso parece no darse; a veces, también, porque la estructura de la tarea y/o la naturaleza del contenido condicionan fuertemente las formas de organización de la actividad conjunta enmascarando los posibles indicadores. $\mathrm{El}$ análisis de las actuaciones de los participantes y de su evolución en el transcurso de las SD/SAC adquiere, en estos casos, un protagonismo absoluto.

La figura 2, que representa el mapa de interactividad de una SD relativa a la enseñanza y el aprendizaje de la numeración y de algunas operaciones elementales de cálculo - SD «salta» correspondiente a un grupo de P4-, ilustra perfectamente el carácter más bien opaco que pueden presentar en ocasiones los mapas de interactividad en lo que concierne al proceso de cesión y traspaso progresivos del control y la responsabilidad.

Como puede comprobarse, la lectura del mapa no permite identificar, en este caso, indicadores claros de una evolución a lo largo de la SD. Las dos primeras sesiones presentan una estructura idéntica: comienzan con un SI más bien breve de organización y preparación del juego $(4,6 \%$ y $15,4 \%$ respectivamente del tiempo total de la sesión), continúan con un SI de partida que ocupa la mayor parte de la sesión $(89,7 \%$ y $81 \%$ respectivamente del tiempo total) y finalizan con un SI de valoración de resultados también muy breve $(5,7 \%$ y $3,3 \%$ respectivamente del tiempo total). En la tercera sesión, el SI de valoración de resultados ocupa un período de tiempo significativamente mayor
$(26,2 \%$ del tiempo total) y aparece además un SI de recapitulación de todo el juego. Ambas variaciones son perfectamente interpretables si atendemos a la planificación previa realizada por la profesora, que incluye una «evaluación» de la actividad - los alumnos han de cumplimentar una ficha sobre el juego realizado- al término de la tercera sesión con la que se cierra la SD.

Todo parece pues indicar que, en este caso, la estructura de la tarea - es decir, la preeminencia de la partida, con los correspondientes turnos, tiradas y rondas de los participantes - condiciona fuertemente las formas de organización de la actividad conjunta que se reflejan en los SI y en los mapas de interactividad. Sin embargo, una lectura más atenta de las informaciones complementarias incluidas en la figura 2 sugiere que, bajo esta uniformidad aparente en la estructura de las sesiones, parece darse una evolución cuyos detalles sólo pueden captarse a través de un análisis más fino centrado en las actuaciones de los participantes. En esta dirección apuntan, por ejemplo, las informaciones relativas al número de errores cometidos en las partidas: 58 en la primera sesión, 22 en la segunda y 7 en la tercera; o la duración media de las tiradas - tiempo total de duración de la partida dividido por el número de tiradas-: 20 segundos en la primera sesión, 14 en la segunda y 14 en la tercera; o aún el tiempo de presencia de la maestra mientras se juegan las partidas: $100 \%$ del tiempo de duración de la partida en la primera sesión, $17,39 \%$ en la segunda y $66,70 \%$ en la tercera.

En suma, para indagar si se produce, y eventualmente cómo se produce, el hipotético proceso de cesión y traspaso progresivos del control y la responsabilidad, es conveniente desplazar el foco del análisis desde los SI y el mapa de interactividad hacia las categorías de actuaciones de los participantes maestra, alumnos que tiran, alumnos que no tiran-, sus interrelaciones - patrones de actuación conjunta - y su evolución a lo largo de la SD. Y esto es justamente lo que se ha hecho en relación, sobre todo, a los tres momentos o fases cruciales de las partidas en los 
que puede detectarse previsiblemente con mayor claridad un posible traspaso: el turno de tirada (desde la atribución del turno de tirada por la maestra, hasta la asunción autónoma del mismó por los participantes, pasando por distintos tipos y grados de supervisión de la maestra o de los otros participantes), la realización de la tirada (desde el control más o menos estricto de la maestra o de los otros participantes, hasta la realización totalmente autónoma de los pasos de la tirada) y la producción, identificación y corrección de errores (disminución progresiva de los errores; evolución progresiva de los tipos de errores; autonomía creciente de los participantes en la identificación y corrección espontánea de los errores cometidos).

Un tercer ejemplo, correspondiente a una SAC observada en la situación de juego diádico con un material relativo al mundo de los gnomos, nos servirá para subrayar el carácter en ocasiones un tanto opaco de los mapas de interactividad y la necesidad de incluir, en este primer nivel de análisis, un estudio más detallado de las actuaciones de los participantes y de su evolución en el transcurso de las $\mathrm{SD} / \mathrm{SAC}$. Las columnas de la figura 3 representan las fases de juego de las seis sesiones de la SAC observada. Cada una de ellas aparece configurada por diferentes tipos de SI, que varían en número y duración. Las divisiones horizontales señalan el final de un SI y el inicio de otro. Para cada SI se indica la categoría a la que pertenece (DE: delimitación del escenario físico y simbólico; $R$ : representación de acontecimientos; P: profundización en características del mundo gnomo y/o humano) y la duración en minutos y segundos. La escala porcentual situada a la izquierda de la figura permite calcular el porcentaje del tiempo total de duración de la fase ocupado por cada SI. Para los SI de representación de acontecimientos y los SI de profundización, se describe además mediante una frase indicativa la historia representada y el tema objeto de profundización respectivamente.

Recuérdese que, contrariamente a lo que sucede con las SD representadas en las figuras 1 y 2 , en esta situación la actividad con- -junta de la madre y su hija no tiene lugar en un contexto social e institucional claramente presidido por el motivo de enseñar y aprender. Por ello, como ya se ha señalado, en este caso el objetivo del primer nivel de análisis es otro: indagar cómo las dos participantes van definiendo progresivamente, mediante la articulación de sus actuaciones respectivas, el contexto situacional en el que desarrollan su actividad. Si miramos desde esta perspectiva la figura 3 , empiezan a cobrar sentido algunas regularidades y tendencias. Así, por ejemplo, vemos que en todas las sesiones hay como mínimo un SI de delimitación del escenario, un SI de representación y un SI de profundización; todas las sesiones comienzan con un SI de delimitación del escenario; excepto en la quinta y la sexta sesión, al SI inicial de delimitación del escenario le sigue un SI de representación; todas las sesiones, excepto la cuarta y la quinta, finalizan con un SI de profundización; los SI de representación ocupan la mayor parte del tiempo en todas las sesiones; en la primera sesión el tiempo ocupado por el SI de delimitación del escenario es considerablemente más elevado que en el resto de las sesiones; en la última sesión, el tiempo ocupado por los SI de profundización es considerablemente más elevado que en el resto de las sesiones; etc.

Todos estos indicadores parecen apuntar hacia una interpretación que podemos resumir brevemente como sigue. Las dos participantes construyen, mediante la articulación de sus actuaciones respectivas, un contexto situacional de juego simbólico organizado en torno a la representación de historias de los gnomos. Para poder representar estas historias, han de comenzar estableciendo una definición inicial de la situación suficientemente compartida (elegir los objetos del material, nombrarlos, etiquetarlos, ponerse de acuerdo sobre sus características y sobre lo que representan, organizar el escenario en el que van a colocarlos y en el que va a desarrollarse la historia, etc), lo cual se lleva a cabo en el transcurso de los SI de delimitación del escenario que abren sistemáticamente todas las sesiones. Esta tarea previa a la representación de acontecimientos es particularmente costosa 
en la primera sesión, cuando las participantes se aproximan por primera vez a la situación y al material. A medida que avanza la SAC y las participantes alcanzan una serie de acuerdos básicos sobre el material, sus características, su organización espacial y su utilización -lo que parece producirse en buena medida durante la primera sesión-, esta forma de organización de la actividad conjunta disminuye considerablemente su presencia en favor de las otras dos. La representación de acontecimientos sigue siendo la forma de organización de la actividad conjunta que predomina en todas las sesiones, pero junto a ella adquiere una cierta importancia la que consiste en prestar una atención especial a determinados aspectos del mundo de los gnomos, lo cual podría ser interpretado tal vez como un indicador de los esfuerzos de las participantes por ampliar su conocimiento compartido de este mundo y, al mismo tiempo, como un indicador de que, al haberse incrementado su conocimiento compartido al respecto, pueden cambiar el foco de sus esfuerzos negociadores.

\section{El segundo nivel de análisis: los significados que se actualizan mediante el discurso educacional}

Recordemos que el segundo nivel de análisis se centra en los significados que actualizan los participantes mediante su actividad discursiva y que son por lo tanto, al menos potencialmente, objeto de negociación. Su finalidad es proporcionar información sobre cómo se produce, cuando se produce, la construcción progresiva de sistemas de significados compartidos. Dos son las preguntas que han guiado nuestra aproximación y que nos han conducido, a través de una serie de tan: teos sucesivos, al procedimiento general de análisis, todavía provisional y en fase de ensayo, cuyos rasgos más destacados se recogen en las páginas siguientes: ¿cuáles son, cómo se presentan y cómo se organizan los significaćos en el transcurso de la SD/SAC?; ¿qué entidad o entidades deben ser objeto directo de indagación para captar los significados que actualizan los participantes mediante su actividad discursiva?
Comenzando por la segunda pregunta, la respuesta parece obvia: de acuerdo con los argumentos expuestos en el apartado correspondiente a las unidades de análisis - y aceptando por tanto de entrada, como allí se indica, que esta opción supone una renuncia a captar algunos aspectos importantes del significado-, vamos a centrar nuestra atención en los mensajes. Esta elección, sin embargo, conlleva dos dificultades o problemas que es necesario resolver.

En primer lugar, hay que precisar qué aspectos concretos de los mensajes conviene someter a indagación para identificar los significados que éstos transmiten; hace falta pues definir los términos y los procedimientos apropiados para llevar a cabo un análisis intramensajes. En segundo lugar, es harto sabido que el significado de un fragmento discursivo no se reduce a la simple adición del significado de los enunciados o mensajes que lo integran. Todos los planteamientos actuales sobre el análisis del discurso coinciden en señalar que una parte importante del significado no tiene su origen en los mensajes o enunciados constituyentes, sino más bien en la forma en que estos mensajes o enunciados están organizados. Pensemos, por ejemplo, en las estructuras IRF -iniciación, respuesta, feedback - , cuyo significado proviene, al menos en parte, de la secuencia estructurada de los tres componentes y no sólo de los mensajes que los integran. Quiere esto decir, en consecuencia, que es también necesario definir los términos y los procedimientos apropiados para llevar a cabo un análisis supra-mensajes. En lo que sigue, y como ilustración de los procedimientos de análisis empleados, nos centraremos exclusivamente en los aspectos vinculados al análisis intra-mensajes. El escaso nivel de formalización y los múltiples interrogantes que todavía subsisten en el análisis supra-mensajes hacen imposible realizar una exposición del mismo sin entrar en los detalles y en la casuística concreta de los resulta. dos, lo que está obviamente fuera del alcance del presente artículo.

Nuestro acercamiento al análisis intramensajes contempla dos aspectos: su contenido referencial y su fuerza ilocutiva. La idea 
directriz es que podemos captar un parte im- portante de los significados que transmiten los mensajes analizando ambos aspectos. Hasta el final del apartado, expondremos cómo puede llevarse a cabo este doble análisis, e ilustraremos el procedimiento utilizado con ejemplos de las SD de enseñanza y aprendizaje de un procesador de textos observadas en los grupos de alumnos universitarios.

Abundando en la idea directriz que guía esta vertiente del análisis, la propuesta de analizar el contenido referencial de los mensajes responde al supuesto de que es posible captar una parte importante de su significado identificando los referentes a los que remiten, es decir, identificando aquello-de-lo-quehablan los mensajes. Este supuesto encuentra su justificación en el concepto de referencia y en el uso que hacen del mismo algunos autores (Lyons, 1983; Brown y Yule, 1983). Al identificar los referentes que aparecen mencionados -o referidos, para ser más exactos- en los mensajes, lo que estamos haciendo es identificar las entidades (objetos, acciones, situaciones, etc.) sobre las que hablan los participantes en una actividad conjunta; es decir, las entidades que actualizan los participantes mediante su actividad discursiva y que constituyen un aspecto del significado de los enunciados. Tal vez no sea superfluo subrayar que los enunciados no contienen referentes, sino expresiones referenciales que remiten, o refieren, a unos referentes determinados. El análisis, en consecuencia, parte necesariamente de las expresiones referenciales que aparecen en los mensajes para inferir, a partir de ellas, las entidades referidas.

Conviene señalar que, en el proceso de identificación de las expresiones referenciales incluidas en los mensajes, hay que tener en cuenta no sólo las que son habitualmente consideradas como tales en la mayoría de enfoques de análisis del discurso (nombres propios, grupos nominales - descripciones definidas, indefinidas, sintagmas nominales cuantificados-, pronombres, deícticos en general, etc.), sino también otras menos habituales como las elipsis y los grupos verbales. Un ejemplo de las primeras es el mensaje «aparece un ícono», en el que cabría tal vez considerar y decidir - aunque para ello habría que tener en cuenta el contexto en el que ha sido producido- que se ha elidido el fragmento «... en la pantalla del ordenador». Un ejemplo de los segundos es la expresión referencial «cargad el procesador de textos» que aparece en el mensaje «ahora cargad el procesador de textos como siempre».

Para poder llevar a cabo un análisis mínimamente preciso del contenido referencial de los mensajes, se requiere partir de una cierta clasificación, por otra parte lo más comprensiva e inequívoca posible, de los referentes que pueden aparecer en los mensajes. En efecto, el contenido referencial de los mensajes, es decir, aquello-de-lo-que-hablan los mensajes, puede situarse en ámbitos muy distintos que, si bien aparecen siempre estrechamente interconectados, vale la pena distinguir en una aproximación analítica.

En el caso de las SD de enseñanza y aprendizaje de un procesador de textos, los contenidos referenciales de los mensajes pueden situarse, en una primera aproximación, en dos grandes ámbitos: el del funcionamiento, características y utilización del PT/ordenador, y el de la gestión y control de las actividades de los participantes. En otras palabras, las entidades referidas en los mensajes pueden tener que ver directamente con los contenidos que son objeto de enseñanza y aprendizaje en las SD (elementos, operaciones, procedimientos, etc., del PT/ordenador) o con la manera de organizar, regular, y controlar la actividad de los participantes en el aula (normas y directrices relativas a qué se puede y qué no se puede hacer, cómo se organizan los grupos de trabajo, cómo se reacciona ante los comportamientos que no respetan las normas fijadas, etc. $)^{8}$.

Una vez establecidos los dos ámbitos referenciales, el esfuerzo de clasificación ha de proseguir en el interior de cada uno de ellos. En el caso de las SD de enseñanza y aprendizaje de un procesador de textos observadas en los grupos de alumnos universitarios, el ámbito referencial de gestión y control de la actividad de los participantes tiene, en realidad, una importancia muy limitada', lo cual no es ajeno probablemente al alto grado de 
organización y estructuración del contenido $\mathrm{y}$ al hecho de que todos los participantes sean adultos escolarizados con una dilatada experiencia en situaciones de educación formal. Las expresiones referenciales que aparecen en los mensajes de estas SD remiten, en su inmensa mayoría, a entidades relativas al ámbito del funcionamiento, características y utilización del PT/ordenador, razón por la cual el esfuerzo de clasificación de los referentes se ha dirigido prioritariamente a este ámbito referencial.

Cuando los participantes hablan del PT/ordenador, es decir, cuando hablan de lo que podríamos denominar el contenido de la enseñanza y el aprendizaje de la SD en sentido estricto, las expresiones referenciales que utilizan remiten a diferentes tipos o categorías de entidades:

Categorias de referentes relativas al ámbito del funcionamiento, características y utilización del PT/ordenador

Acciones. Ejecuciones o manipulaciones físicas, de carácter discreto, que realiza el usuario del PT/ordenador en el manejo habitual del mismo (por ejemplo, mover el ratón, meter el disco, pulsar una o varias teclas, hacer un «clic» o un «doble clic» en el interruptor del ratón, etc.). Ejemplos de mensajes que contienen items de contenido pertenecientes a esta categoría:

[el disco se coge siempre por la parte de la etiqueta ${ }^{10}$ ]

(Grupo universitarios sin conocimientos previos, Sesión 1, SI 1)

[cuando apretáis esta tecla automáticamente se situaría al principio de la columna de tabulador]

(Grupo universitarios sin conocimientos previos, Sesión 4, SI 2)

Procedimientos. Paquetes organizados de acciones ejecutables por el usuario del PT/ordenador para lograr un efecto u objetivo determinado (por ejemplo, abrir un menú, seleccionar un bloque de texto, modificar el formato de un texto, cerrar una ventana, desplazar el curso, etc.). Ejemplos de mensajes que contienen ítems de contenido pertenecientes a esta categoría:

[para activar la regla hemos de hacer siempre lo mismo]

(Grupo de universitarios sin conocimientos previos, Sesión 1, SI 8)

[ahora cargad el procesador de textos como siempre]
(Grupo de universitarios sin conocimientos previos, Sesión 4, SI 1)

Elementos. Objetos o entidades - de naturaleza física, icónica o de otro tipo- relativos al entorno de trabajo del PT/ordenador (por ejemplo, la pantalla, el ratón, el ícono del dico, el puntero, un fragmento de texto, la memoria del ordenador, etc.). Ejemplos de mensajes que continen items de contenido pertenecientes a esta categoría:

[y si os fijáis el ... la cajita tiene una tecla un interruptor]

(Grupo de universitarios sin conocimientos previos, Sesión 1, SI 1)

[este tabulador hace lo contrario]

(Grupo de universitarios sin conocimientos previos, Sesión 4, SI 2)

Operaciones. Efectos o resultados «producidos por el ordenador» como consecuencia - habitualmente- de una acción o un procedimiento específico realizado por el usuario durante el manejo del mismo (por ejemplo, que el puntero se desplace, que aparezca una ventana en la pantalla, que el formato de un texto se modifique, etc.). Ejemplos de mensajes que continen items de contenido pertenecientes a esta categoría:

[va a salir una ventana que nos va a mostrar el contenido que hay dentro del disco]

(Grupo de universitarios sin conocimientos previos, Sesión 1, SI 1)

[y automáticamente transformaría todo lo que bemos seleccionado con ese tipo de letra]

(Grupo de universitarios sin conocimientos previos, Sesión 2, SI 2)

Algunos comentarios sobre la clasificación precedente pueden ser útiles para precisar el interés y la pertinencia teórica de esta vertiente del análisis intra-mensajes y para concretar algunos aspectos del procedimiento metodológico seguido. En primer lugar, senalemos que las categorías descritas surgen de un proceso «de ida y vuelta» entre teoría y datos. Así, las categorías propuestas responden y se apoyan, por un lado, tanto en un análisis cognitivo de la tarea de edición de textos como en los principios que forman parte del marco teórico de la investigación; pero, por otro lado, son el resultado de un proceso de refinamiento progresivo de las categorías iniciales a partir del contraste contínuo con los datos, hasta encontrar un sistema de clasificación susceptible, al mismo tiempo, de ajustarse a los datos de manera no artificiosa y 
de conservar un referente teórico claro. Esto permite -al igual que sucede con los diferentes tipos de SI identificados en el primer nivel de análisis- que los posibles parámetros de variación y evolución de presencia, frecuencia, distribución, etc. de las distintas categorías de referentes sean interpretables desde los principios teóricos y las hipótesis directrices que enmarcan y guían el proyecto de investigación en su conjunto.

En segundo lugar, los mensajes pueden incluir una o más expresiones referenciales y, por tanto, remitir a uno o más ítems de contenido referencial. En el caso, por ejemplo, del mensaje «vamos a ver ahora como podemos meter el discon, aparece una expresión referencial -meter el disco-, que remite, en la clasificación anterior, a una acción. En cambio, en el mensaje «si movemos el ratón, la flecha se desplaza por la pantalla del ordenador», aparecen tres expresiones referenciales que, en nuestra clasificación, remiten respectivamente a una acción - mover el ratón-, una operación -la flecha se desplaza- y un elemento - la pantalla del ordenador. En suma, un mensaje remite a tantos items de contenido como expresiones referenciales aparecen en el mismo.

En tercer lugar, una misma entidad puede estar referida mediante expresiones referenciales diversas; así, en el primer ejemplo de la categoría «elementos», las expresiones referenciales «una tecla» $y$ «un interruptor» tienen el mismo contenido referencial (interruptor del ratón), que pertenece a la categoría de los elementos.

De este modo, podemos obtener, para cada uno de los mensajes, una descripción que incluye las entidades referidas en el mismo, su orden de enunciación y la categoría a la que pertenecen. El mapa de contenidos referenciales así elaborado permite abordar una serie de cuestiones de sumo interés desde la perspectiva teórica del proyecto. Permítasenos enunciar, sin ánimo alguno de exhaustividad, algunas de las posibilidades de análisis - más evidentes, y también más atractivas. Es posible, por ejemplo, a partir de los mapas de contenidos referenciales:

(i) Relacionar la frecuencia de aparición de referentes concretos y/o de categorías de referentes (acciones, procedimientos, operaciones, elementos) con los resultados de la evaluación sumativa realizada por los alum. nos al final de las SD.

(ii) Indagar si hay algunos referentes $y / o$ categorías de referentes que aparecen más estrechamente relacionados con unos determinados tipos de SI.

(iii) Indagar si hay una evolución significativa a lo largo de la SD de las categorías de referentes y, en su caso, si esta evolución se verifica sólo en unos determinados tipos de SI o para el conjunto de ellos.

(iv) Indagar si aparecen en los mensajes configuraciones de tipos de referentes $y$, en caso afirmativo, si se vinculan o no de forma prioritaria con determinados tipos de SI y si su frecuencia de aparición evoluciona significativamente a lo largo de la SD. El análisis de las configuraciones proporciona indicadores sobre el proceso de construcción de sistemas de significados compartidos. En este sentido, por citar un ejemplo obvio, cabe interpretar el hecho de que, en la SD representada en la Figura 1, la frecuencia de la configuración acción-operación disminuya progresivamente a medida que avanza la SD, mientras que la frecuencia de la configuración procedimiento-operación se incremente también progresivamente a medida que avanza la SD. O también, que los mensajes con una sola entidad referida aparezcan sobre todo en la primera sesión de las SD; o aún que los mensajes con una, dos o más entidades referidas de la categoría elementos aparezcan sobre todo en los primeros SI de la primera sesión para desaparecer prácticamente después.

(v) Las configuraciones de tipos de referentes brindan asimismo una plataforma para adentrarse en el análisis de algunos aspectos del significado de los enunciados que van más allá de su contenido referencial. Así, por ejemplo, es posible seleccionar los mensajes en los que aparecen referidas dos o más entidades pertenecientes a dos o más categorías de referentes (acción-operación, pongamos por caso) y tratar de responder las siguientes preguntas: ¿qué tipo de relaciones logico- 
semánticas (causales, temporales, de correspondencia, etc) se establecen entre las dos entidades referidas?, ¿se constata una evolución de los tipos de relaciones identificadas a medida que avanza la SD?, ¿son estas relaciones distintas de las que aparecen, pongamos por caso, en los mensajes con una configuración procedimiento-operación?, etc.

Lo dicho hasta aquí basta para ilustrar el interés que puede revestir un análisis del contenido referencial de los mensajes y el procedimiento seguido para llevarlo a cabo. Sin embargo, como hemos señalado en repetidas ocasiones, el contenido referencial de los mensajes -incluyendo el que corresponde al ámbito de gestión y control de la actividadsólo refleja una pequeña parcela de los significados que actualizan los participantes mediante su actividad discursiva. De acuerdo con nuestro planteamiento inicial, y sin abandonar el nivel de los mensajes, una parte importante de los significados que transmiten reside en su fuerza ilocutiva. Vamos pues, en lo que sigue, a ocuparnos de este aspecto.

Muy brevemente, el concepto de fuerza ilocutiva está estrechamente vinculado a la teoría de los actos de habla de Austin (1962), según la cual algunos enunciados (como, por ejemplo, «te apuesto cien pesetas a que saltan los plomos», o «con estas palabras, doy por concluida la sesión», etc.) deben ser tratados como verdaderas acciones que el locutor ejecuta «haciendo cosas con palabras». Ahora bien,

«By extension, it becomes possible to suggest that
in uttering any sentence, a speaker could be seen
to have performed some act, or to be precise,
an illocutionary act. Conventionally associated
with each illocutionary act is the force of the
utterance which can be expressed as a perfor-
mative such as «promise» or «warn».
(Brown y Yule, 1983, p. 232 . Subrayado aña-
dido)

Contrariamente pues a lo que sucede con el análisis del contenido referencial, en este caso no se categorizan fragmentos de los mensajes, sino que cada mensaje como totalidad tiene una determinada fuerza ilocutiva. Los tres tipos básicos de actos de habla - hacer aseveraciones, plantear preguntas y dar órdenes - propuestos por Lyons (1983) han sido nuestro punto de partida.

De este modo, en lo que concierne a las SD de enseñanza y aprendizaje de un procesador de textos, hemos llegado a establecer -tras los correspondientes ensayos y «viajes de ida y vuelta» entre la propuesta inicial de Lyons y los datos disponibles - la siguiente clasificación ${ }^{11}$ :

Clasificación de los mensajes según su fuerza ilocutiva. SD de enseñanza y aprendizaje de un procesador de textos.

Aseveraciones. Enunciados que suponen, por parte de quien los produce, la adopción de un "compromiso epistémico» en relación a lo que se afirma o se niega en los mismos; es decir, un compromiso con la asunción como verdad de lo que se afirma o con la falsedad de lo que se niega. Se distinguen tres tipos de aseveraciones:

(i) Metaenunciados. Aseveraciones mediante las cuales el profesor informa a los alumnos en relación a lo que va a ocurrir en el desarrollo habitualmente inmediato- de la sesión anunciando los contenidos y las actuaciones de la actividad conjunta. Ejemplos de mensajes incluidos en esta categoría:

[vamos a ver a continuación cómo podemos modificar el formato del texto]

(Grupo de universitarios sin conocimientos previos, Sesión 1, SI 8)

[vamos a ver hoy lo que son las cabeceras, pies y notas a pie de página]

(Grupo de universitarios sin conocimientos previos, Sesión 3, SI 2)

(ii) Enunciados ILE. Aseveraciones mediante las cuales un participante presenta -identifica, localiza y/o etiqueta - algún elemento del entorno de trabajo del PT/ordenador sin añadir otro tipo de informaciones al respecto. Ejemplos de mensajes incluidos en esta categoría: [el ordenador es esto de aquí]

[lo otro es el ratón]

(Grupo de universitarios sin conocimientos previos, Sesión 1, SI 1)

[para desplazar esta flecha y seleccionar lo que queramos tenemos esta cajita ...]

[que se llama teclado]

(Grupo de universitarios sin conocimientos previos, Sesión 2, SI 1)

(iii) Enunciados informativos. Aseveraciones me diante las cuales un participante ofrece algún tipo de información sobre las entidades referidas en el enunciado que va más allá de la simple presentación -identificación, localización, 
etiquetado- de las mismas. Ejemplos de mensajes incluidos en esta categoría:

[en el momento en que estamos con el cursor aquí el formato es el que corresponde con la parte del texto que estamos]

(Grupo de universitarios sin conocimientos previos, Sesión I, SI 8)

[pero tener en cuenta que en la cabecera sale un símbolo que representa todos los números de las hojas]

(Grupo de universitarios sin conocimientos previos, Sesión 3, SI 2)

Ordenes. Enunciados que suponen, por parte de quien los produce, la adopción de un «compromiso deóntico» en relación a lo que se expresa; es decir, un compromiso con la realización de las acciones y/o procedimientos expresadas en el mensaje. Ejemplos de mensajes incluidos en esta categoría:

[ahora vosotros apagaréis el interruptor de atrás]

(Grupo de universitarios sin conocimientos previos, Sesión 1, SI 8)

[hacéis un doble clic encima del documento ... ¿eh?]

[os poneis encima del documento]

(Grupo de universitarios sin conocimientos previos, Sesión 2, SI 1)

Preguntas. Enunciados que implican, por parte de quien los produce, un requerimiento de información al interlocutor o interlocutores en relación a las entidades referidas en los mismos. Ejemplos de mensajes incluidos en esta categoría:

[si a alguien no le sale esto que me lo diga] [¿os sale a todos esto?]

(Grupo sin conocimientos previos, Sesión 2, SI 1]

[ésta sería una forma de justificar perdón de colocar los tabuladores para crear columnas] [en principio no plantea ningún problema ¿no?] [¿se entiende como funciona?]

(Grupo de universitarios sin conocimientos previos, Sesión 4, SI 2)

Esta clasificación permite captar nuevos aspectos del significado de los mensajes. En primer lugar, facilita una serie de análisis específicos directamente relacionados con el tipo de fuerza ilocutiva que representa cada categoría. Así, puede ser utilizada como base para indagar si existen relaciones consistentes entre determinados tipos de SI y la fuerza ilocutiva de los mensajes que aparecen en ellos; si hay mensajes con una determinada fuerza ilocutiva que están total o parcialmente ausentes en algunos tipos de SI; si hay una evolución a lo largo de la SD de los mensajes con diferente fuerza ilocutiva; etc. En segundo lugar, al cruzar los mensajes con diferente tipo de fuerza ilocutiva con el mapa de contenidos referenciales, aparecen aspectos del significado hasta ahora inéditos. Unos breves comentarios sobre los metaenunciados nos permitirán ilustrar ambas posibilidades.

Los metaenunciados, de acuerdo con la definición propuesta, son mensajes mediante los cuales uno de los participantes - casi siempre el profesor en las SD de enseñanza y aprendizaje de un procesador de textos- «informa al estudiante sobre lo que va a ocurrir, o justifica lo que va a ocurrir, en el desarrollo de la lección» (Ramírez, 1988, p. 163). Los metaenunciados son uno de los instrumentos que utiliza el profesor para definir la situación y llamar la atención de los alumnos sobre su definición de la situación. En este sentido, la presencia o ausencia de metaenunciados en los diferentes tipos de SI y su evolución en el transcurso de la SD proporciona informaciones relevantes para comprender cómo se organiza la actividad conjunta del profesor y los alumnos.

Pero además los metaenunciados son mensajes que pueden tener contenidos referenciales diversos. Así, por ejemplo, podemos encontrar metaenunciados en los que las entidades referidas pertenecen a la categoría de los elementos («vamos a empezar a conocer un poco el teclado»), a la categoría de las acciones («y vamos a ver cómo podemos meter el disco ¿eh?), a la categoría de las operaciones («veremos como el ordenador no guarda los cambios si no se lo decís»), a la categoría de los procedimientos («vamos a ver a continuación cómo podemos modificar el formato del texto»), o a varias de ellas.

El establecimiento de subcategorías de metaenunciados en función de los tipos de entidades referidas en ellos es relativamente fácil a partir del mapa de contenido referencial construído según el procedimiento anteriormente descrito. De este modo, y en la medida en que las diferentes subcategorías son interpretables en términos de construcción progresiva de sistemas de significados compartidos, el estudio de su presencia y evo- 
lución en los diferentes tipos de SI a lo largo de la SD permite explorar algunas hipótesis relevantes. Por ejemplo, un incremento progresivo en la frecuencia de aparición de metaenunciados con un contenido referencial de procedimientos y operaciones puede ser interpretado -en el caso, por supuesto, de que no produzcan rupturas en el flujo de la actividad conjunta - como un indicador de que los participantes comparten significados ca$\mathrm{da}$ vez más amplios y complejos sobre las características, funcionamiento y utilización del PT/ordenador. Y a la inversa, el mantenimiento de una frecuencia elevada de aparición de metaenunciados con un contenido referencial de elementos y acciones en fases avanzadas de la SD puede interpretarse, hasta cierto punto, como un indicador de que los participantes tienen dificultades para progresar en la construcción de significados compartidos cada vez más amplios y profundos al respecto.

\section{ALGUNAS CUESTIONES ABIERTAS}

Hemos señalado repetidas veces, en el transcurso de este artículo, el carácter tentativo y provisional de la mayoría de nuestras propuestas, especialmente de las que conciernen a los procedimientos y al modelo global de análisis. Quisiéramos ahora, en este último apartado, insistir de nuevo sobre las limitaciones y la provisionalidad del enfoque metodológico adoptado subrayando sin embargo, al mismo tiempo, el interés que encierra para el estudio de los mecanismos de influencia educativa. La descripción que precede de las unidades y niveles de análisis, así como los ejemplos que han servido para ilustrar unas y otros, muestra a nuestro juicio que las opciones metodológicas de fondo son al mismo tiempo heurísticamente potentes, susceptibles de generar procedimientos de análisis concretos y viables $y$, lo que es quizás aún más importante, respetuosas con las exigencias impuestas por las ideas directrices y los principios básicos del proyecto. Sin embargo, esta descripción pone igualmente de relieve que son todavía numerosos los puntos necesitados de un mayor esfuerzo de elaboración teórica, de profundización y precisión conceptual y, por supuesto, de concreción y definición operacional.

Incluso en lo que concierne al primer nivel de análisis, en el que hemos alcanzado a nuestro entender un nivel de precisión relativamente satisfactorio, subsisten ambigüedades de cierta importancia y son varios los aspectos que merecen ser profundizados, ampliados y concretados. Así, por ejemplo, subsiste la duda de si los criterios que hemos utilizado para identificar y segmentar los SI son aplicables a SD/SAC con características distintas de las que constituyen nuestro corpus de datos. Cabe preguntarse si el Segmento de Interactividad, tal como ha sido definido, es una unidad de análisis útil para caracterizar la actividad conjunta en situaciones débilmente estructuradas, es decir, cuando el contenido no está delimitado y/o cuando la tarea no ha sido claramente establecida de antemano y no es compartida por los participantes. Más aún, cabe preguntarse si en estos casos, en los que la verdadera tarea de los participantes es ponerse de acuerdo para desarro. llar una actividad conjunta, tiene sentido utilizar los Segmentos de Interactividad entendidos como unas formas determinadas de organización de la actividad conjunta- como unidades de análisis.

En otro orden de consideraciones, y sin abandonar el primer nivel de análisis, la lógica seguida para establecer los SI parte, como hemos visto, de las actuaciones de los participantes, y utiliza el constructo de estructura de participación para seleccionar, identificar y clasificar las actuaciones teóricamente más relevantes desde la perspectiva de los mecanismos de influencia educativa. Las reservas, en este caso, se refieren no sólo al filtro teórico utilizado - que conduce a una determinada tipología de actuaciones, verdadera piedra angular de todo el procedimiento-, sino también, y lo que es más importante, a la integración conceptual todavía muy limitada que podemos ofrecer, hoy por hoy, de los tres constructos básicos: actuaciones, estructura de participación y Segmentos de Interactividad.

Las limitaciones y la provisionalidad de nuestra aproximación empírica son aún más 
evidentes, si cabe, en lo que respecta al segundo nivel de análisis. Es menester, en primer lugar, una mayor elaboración teórica de la propia unidad de análisis - el mensajea la luz de los resultados obtenidos $y$, sobre todo, a la luz de las dificultades encontradas para identificar y segmentar los mensajes. Los criterios utilizados a este respecto pueden y deben ser precisados todavía más con el fin de hacer frente a la compleja casuística reflejada en los registros observacionales, especialmente cuando corresponden a situaciones con un fuerte componente manipulativo y/o con una escasa actividad discursiva de los participantes.

En segundo lugar, y en relación a lo que hemos denominado análisis intra-mensajes, conviene recordar que, en la confección del mapa de contenidos referenciales, hemos partido de una categorización previa de los ámbitos referenciales y de los items de contenido de cada uno de ellos. Esta tarea se ve enormemente facilitada cuando - como sucede en la SD utilizada como ejemplo en la exposición - el ámbito referencial de gestión y control tiene una presencia muy secundaria y cuando el ámbito referencial relativo al contenido de la enseñanza y el aprendizaje está relativamente bien definido de entrada y posee, además, un alto grado de organización y estructuración interna. Las circunstancias, sin embargo, no son siempre tan favorables. Es frecuente, por ejemplo, que los contenidos - y/o la tarea - en torno a los cuales se organiza la actividad conjunta de los participantes no estén tan bien delimitados de entrada; o que, estando más o menos bien delimitados, los participantes inicien la actividad conjunta con definiciones sustancialmente distintas de la situación, lo que puede llevarles a referirse contínuamente, sobre todo en las primeras fases de la SD/SAC, a la manera de organizar, regular, y controlar sus actuaciones respectivas. Cuando esto sucede, es necesario atender simultáneamente a los dos ámbitos referenciales -el de los contenidos de la enseñanza y el aprendizaje y el de gestión y control- y el establecimiento de categorías de items de contenido se complica considerablemente.
El procedimiento es entonces costoso, y lo es porque la clasificación de los items de contenido en los dos ámbitos referenciales no puede hacerse a priori, de una manera general, para todo tipo de situaciones de actividad conjunta. Sería en efecto contradictorio proponer una tipología general de items de contenido susceptible de ser aplicada a cualquier situación de actividad conjunta y seguir manteniendo por ejemplo, al mismo tiempo, que la naturaleza del contenido y/o la estructura de la tarea son un elemento decisivo para entender cómo se organiza la actividad conjunta.

Algo similar cabe decir de la clasificación de los mensajes en función de su fuerza ilocutiva. Es cierto que, en esta vertiente del análisis intra-mensajes, hemos partido de los tres tipos de actos ilocutivos que algunos autores consideran como «universales» 0 «básicos»: hacer aseveraciones, plantear preguntas y dar órdenes. Sin embargo, la clasificación finalmente utilizada metaenunciados, enunciados ILE, enunciados informativos, órdenes y preguntas- para analizar este aspecto del significado de los mensajes es el resultado de un proceso de ida y vuelta entre la clasificación inicial y los datos y refleja por tanto, en gran medida, las características propias de las SD correspondientes.

Sin embargo, y pese a todas estas reservas y limitaciones - a las que hay que añadir, por supuesto, las ya mencionadas en el apartado anterior a propósito del análisis supramensajes y que no es necesario repetir aquí-, el procedimiento adoptado proporciona a nuestro juicio un base suficientemente amplia para explorar algunas hipótesis sobre los mecanismos semióticos que intervienen en el proceso de construcción progresiva de sistemas de significados compartidos en el transcurso de las SD/SAC. Así, por mencionar sólo algunos ejemplos obvios, podemos utilizar las informaciones proporcionadas por el mapa de contenidos referenciales y la clasificación de los mensajes según su fuerza ilocutiva para indagar si se produce o no un aumento progresivo de la intersubjetividad de los participantes en el transcurso de las SD (en este sen- 


\section{8}

tido podría interpretarse, pongamos por caso, una disminución progresiva de la frecuencia de aparición de items de contenido correspondientes a las categorías de elementos y acciones y, correlativamente, un incremento progresivo de la frecuencia de aparición de items de contenido correspondientes a las categorías de procedimientos y operaciones); si efectivamente, como podría postularse desde una perspectiva vygotskiana, este aumento de la intersubjetividad a medida que avanzan las SD se traduce en una disminución progresiva del habla social externa contextualizada con predominio de los aspectos indexicales de la significación y, correlativamente, en un aumento progresivo del habla social externa descontextualizada con un predominio de los aspectos más estables de la significación; si, a medida que avanzan las SD, los mensajes producidos por los participantes requieren una mayor información del contexto para poder ser interpretados; etcétera.

Las informaciones proporcionadas por los mapas de contenido referencial y por la clasificación de los mensajes según su fuerza ilocutiva - sobre todo cuando se consideran conjuntamente y se utilizan de manera cruzada - proporcionan indicadores útiles para explorar estas y otras hipótesis de naturaleza similar sobre los mecanismos semióticos subyacentes a la construcción progresiva de sistemas de significados compartidos en el transcurso de las SD/SAC. Estos indicadores, sin embargo, no aparecen de manera inmediata, sino que han de construirse mediante un proceso de elaboración teórica y metodológica que está todavía, en gran parte, por hacer. En suma, y éste es el argumento principal que resume los comentarios precedentes, el segundo nivel de análisis, tal como ha sido presentado, no proporciona una respuesta inmediata a las preguntas sobre la construcción progresiva de sistemas de significados compartidos que nos planteábamos en la primera parte de este artículo. Sí que proporciona, en cambio, informaciones útiles para explorar algunos mecanismos semióticos que subyacen supuestamente a este proceso de construcción.
Quisiéramos ahora poner punto final a este artículo con un comentario, más bien una breve anotación, sobre el análisis de la interactividad en la perspectiva de una aproximación global al estudio de la práctica educativa. Afirmábamos en los comentarios introductorios que nuestro enfoque teórico postula que algunos mecanismos de influencia educativa particularmente importantes y decisivos se sitúan en el campo de lo interpersonal. Pero manifestábamos igualmente nuestra convicción de que el análisis de las pautas interactivas -incluso con la ampliación del foco de interés que supone el concepto de interactividad - no es el único análisis pertinente para una mejor comprensión de la práctica educativa.

Es evidente que si queremos comprender, por ejemplo, qué aprenden finalmente unos alumnos en una clase de matématicas y cómo lo aprenden, tendremos que sumergirnos en un análisis de lo que sucede en dicha clase; tendremos que analizar cómo los alumnos y el profesor organizan su actividad conjunta, cuáles son los contenidos y las tareas que vertebran las actividades de enseñanza y aprendizaje en el aula, cómo se produce - $\mathrm{O}$ no se produce - la cesión progresiva del control y la responsabilidad, hasta qué punto se amplian efectivamente los significados compartidos por uno y otros a medida que se desarrolla la clase, qué sucede cuando el profesor da erróneamente por supuesto que los alumnos comparten su definición de la situación, etc. Qué duda cabe que, una vez realizado este análisis, nuestra comprensión de qué han aprendido -o no han aprendidolos alumnos, cómo y por qué se habrá enriquecido considerablemente. Más aún, este análisis es a todas luces imprescindible para comprender qué han aprendido realmente los alumnos de nuestro hipotético ejemplo gracias a la ayuda que han recibido de su profesor, como consecuencia de la influencia educativa que sobre ellos ha ejercido su profesor.

Es en este sentido que el análisis de la interactividad -0 , si se prefiere, de las formas de organización de la actividad conjuntaconstituye a nuestro entender un aspecto al mismo tiempo esencial e irrenunciable para 
una mejor comprensión de la práctica educativa. Y en este sentido también, dicho sea de paso, que algunos procedimientos expuestos en las páginas del presente artículo ${ }^{12}$ para llevar a cabo este análisis pueden tal vez convertirse, con las correcciones oportunas y convenientemente utilizados, en instrumentos para la reflexión sobre la propia actividad docente en el contexto de los programas de formación del profesorado.

Sería sin embargo una ingenuidad suponer que la comprensión de lo que sucede en nuestra hipotética clase de matemáticas puede agotarse mediante una análisis de la interactividad. El triángulo interactivo formado por los alumnos, el profesor y los contenidos cuyas características y dinámica concreta aspira a captar y comprender el análisis de la interactividad - aparece de hecho encajado en una serie de sistemas más amplios (la escuela y los diferentes niveles de organización y gestión del Sistema Educativo) y está estrechamente relacionado con otros sistemas paralelos (los sistemas de educación no escolar). Una aproximación global al análisis de la práctica educativa que tiene lugar en las escuelas debería contemplar estos diferentes sistemas y sus interrelaciones. $\mathrm{Y}-\mathrm{al}$ menos desde la perspectiva teórica y desde las preocupaciones que han guiado nuestro trabajodebería hacerlo situando en el punto de partida el interrogante de cómo se plantean, en cada uno de estos sistemas, las relaciones entre los tres vértices del triángulo interactivo: las formas o saberes culturales objeto de apropiación, los niños y niñas que han de apropiárselos y los agentes educativos que actúan como mediadores.

\section{Notas}

${ }^{1}$ El proyecto de investigación descrito en este artículo ha sido realizado gracias a una subvención de la Dirección General de Investigación Cientifica y Técnica (DGICYT, PB87-0060. Título del proyecto: «Contexto, referencia y construcción de significados en la interacción educativa». Investigador principal: César Coll). La redacción del mismo se ha visto facilitada por la concesión de una ayuda del Departament d'Ensenyament de la Generalitat de Catalunya en el marco de la Convocatòria d'adjudicació d'ajuts als Departaments $i$ Instituts de recerca universitaris per tal d'alliberar professorat ordinari per a la seva dedicació a projectes de recerca (curso 1991-92). En el artículo se retoman y sintetizan las principales ideas expuestas en una ponencia presentada en el «Primer Encuentro sobre líneas de investigación en Psicología de la Educación en España», organizado por el Instituto Municipal de Investigación en Psicología Aplicada a la Educación (IMIPAE), la revista Infancia y Aprendizaje y el Departamento de Psicología Evolutiva y de la Educación de la Universidad de Barcelona en septiembre de 1991.

${ }^{2}$ Estas ideas directrices y principios básicos se han ido configurando progresivamente en el transcurso de la realización del proyecto, y tienen diferentes orígenes. Entre estos orígenes cabe destacar una serie de trabajos sobre la actividad exploratoria y la actividad de juego en el parvulario realizados entre 1979 y 1981 aproximadamente («La actividad exploratoria y la actividad lúdica como instrumentos básicos de la enseñanza preescolar». Proyecto subvencionado por el INCIE en el marco del VIII Plan de Investigación Educativa; los trabajos fueron llevados a cabo en el Departamento de Psicología Evolutiva y Diferencial de la Universidad de Barcelona por el Grupo de Investigaciones Psicopedagógicas, integrado, bajo la dirección de C. Coll, por E. Bassedas, M. Forns, A. Freixas, G. Martínez, M. Maté, M. Miras, M. Rossell, D. Sala, I. Solé y C. Triadó; pueden consultarse, a este respecto, los artículos publicados por los miembros del Grupo de Investigaciones Psicopedagógicas en el número 81-82 de la revista Cuadernos de Pedagogia (1981); también, Bassedas y Solé (1979) y Rossell (1980); un trabajo de tesis doctoral realizado entre 1984 y 1987 sobre la enseñanza del inglés como segunda lengua en el B.U.P. (Pla, 1989); y una serie de trabajos sobre el diseño y el desarrollo del currículum escolar en los que hemos estado fuertemente implicados algunos de nosotros desde 1983 aproximadamente (Coll, 1987, entre otros). El proyecto tiene como antecedente inmediato un seminario interno de lectura y discusión desarrollado en el Departamento de Psicología Evolutiva y de la Educación de la Universidad de Barcelona durante el curso 1986-87.

${ }^{3}$ En las expresiones «lo que hace el alumno», «lo que hace el profesor», etc., el verbo «hacer» se utiliza en sentido amplio e incluye, por supuesto, «lo que se dice», la actividad discursiva, considerada no como un tipo especial de actividad que ha de ser estudiada al margen de otros tipos de actividad, sino como parte integrante de la actividad global del individuo e integrada en ella. Seguimos en este 
punto la sugerencia de Wertsch cuando recuerda, en sus comentarios sobre el concepto de babla (speech) utilizado por Vygotsky y sus seguidores, que «they [Vygotsky and bis followers] insist that speech can be understood only if it is viewed as being part of ongoing buman activity" (Wertsch, 1979, p.4).

${ }^{4}$ Las cintas de video nos han sido amablemente facilitadas por R.G.B. Internacional.

${ }^{5}$ Centro «Torrebonica» de la Fundación «La Caixa» emplazado en Terrassa.

"Conviene subrayar que, como muestra la caracterización realizada, las etiquetas «explicación», «seguimiento», ... remiten a actuaciones específicas de la situación de enseñanza y aprendizaje estudiada, y no a fenómenos generales identificables en cualquier situación distinta de la observada.

${ }^{7}$ Se trata de las SD correspondientes al juego «salta». El material está formado por un tablero, uno (P4) o dos (P5) dados y seis fichas de colores. En el tablero se han dibujado cincuenta casillas sin numerar que han de recorrer las fichas de los jugadores. En la casilla de partida hay la imagen de un conejo y en la de llegada una zanahoria. Por turno, cada uno de los seis participantes lanza el dado y avanza su ficha tantas casillas como indica el número obtenido. Cuando se utilizan dos dados, hay que sumar los números de ambos para determinar cuántas casillas debe avanzar la ficha. Gana el jugador que llega antes al final del recorrido - casilla en la que está representada la zanahoria - con una tirada que le permite avanzar exactamente el mismo número de casillas que separan a su ficha de la meta.

${ }^{8} \mathrm{La}$ delimitación de los dos ámbitos referenciales - el de los contenidos de la enseñanza y aprendizaje de la SD y el de gestión y control de la actividad de los participantes- es bastante más problemática cuando no están claramente definidos los contenidos y/o las tareas en torno a los cuales se organiza la actividad conjunta de los participantes; o también cuando no existe una definición más o menos precisa y compartida del contexto social e institucional, como sucede por ejemplo en las SAC relativas al mundo de los gnomos.

${ }^{9}$ No sucede lo mismo en las otras SD/SAC que hemos observado, en las que son frecuentes los mensajes con expresiones referenciales que remiten al ámbito de la gestión y control de la actividad de los participantes.

${ }^{10}$ Los fragmentos de los mensajes que se han subrayado corresponden a las expresiones referenciales utilizadas, en cada caso, para inferir los referentes de la categoría ejemplificada.

${ }^{11}$ El alcance de esta clasificación se limita a las SD de enseñanza y aprendizaje de un procesador de textos. Aún aceptando que los tres tipos de actos de habla propuestos por Lyons son universales y básicos, la clasificación de los mensajes en función de su fuerza ilocutiva depende, en cada SD/SAC, de la naturaleza del contenido y de la estructura de la tarea en torno a los cuales se organiza la actividad conjunta.

${ }^{12}$ Estamos pensando sobre todo en los procedimientos correspondientes al primer nivel de análisis que, como se recordará, conciernen básicamente a las actuaciones de los participantes, a los Segmentos de Interactividad y a las Configuraciones de Segmentos de Interactividad. La complejidad de los procedimientos correspondientes al segundo nivel de análisis, centrado en los mensajes, hace mucho más difícil imaginar su posible utilización sistemática en la formación del profesorado.

\section{Referencias}

Austin, J. L. (1962). How to do things with words. Oxford: Clarendon Press.

BASSEDAS, E., Y SOLE, I. (1979). L'activitat de l'alumne com a element d'anàlisi psicopedagògica: l'educació de pàrvuls a Catalunya (1900-1978). Tesis de Licenciatura no publicada. Facultad de Filosofía y Ciencias de la Educación. Sección de Psicología. Universidad de Barcelona.

Brown, G. Y Yule, G. (1963). Discourse analysis. Cambridge: Cambridge University Press.

Cazden, C. B. (1990). El discurso del aula. En M. C. Wittrock (Ed.), La investigación de la enseñanza, III. Profesores y alumnos. Barcelona: Paidós, pp. 627-709 (Publicación original en inglés en 1986).

Cazden, C. B. (1991). El discurso en el aula. El lenguaje de la enseñanza y el aprendizaje. Barcelona: Paidós/M.E.C. (Publicación original en inglés en 1988).

Colı, C. (1981). Naturaleza y planificación de las actividades en el parvulario. Cuadernos de Pedagogía, 1981, 81-82 (Reproducido en C. Coll, Aprendizaje escolar y construcción del conocimiento. Barcelona: Paidós, 1990, pp. 65-79).

Colt, C. (1983). Interactividad e interacción. Bases para un análisis psicoeducativo de la gestión del proceso de enseñanzalaprendizaje. Documento interno no publicado. Departamento de Psicología Evolutiva y Diferencial. Facultad de Filosofía y Ciencias de la Educación. Universidad de Barcelona.

Colt. C. (1987). Psicología y curriculum. Una aproximación psicopedagógica a la elaboración del curriculum escolar. Barcelona: Laia (Reeditado por Editorial Paidós, 1991).

Coll, C. (1988). Conocimiento psicológico y práctica educativa. Introducción a las relaciones entre psicología y educación. Barcelona: Barcanova.

Colt. C. (1990). Un marco de referencia psicológico para la educación escolar: la concepción constructivista del aprendizaje y de la enseñanza. En C. Coll, J. Palacios y A. Marchesi (Comps.), Desarrollo psicológico y educación. II. Psicología de la Educación. Madrid: Alianza, pp. 435-453. 
Edwards, D. Y Mercer, N. (1988). El conocimiento compartido. El desarrollo de la comprensión en el aula. Barcelona: Paidós/M.E.C. (Publicación original en inglés en 1987).

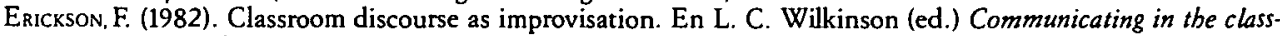
room. New York: Academic Press.

GreEn, J. L.; WeAde, R. Y Graham, K. (1988). Lesson construction y student participation: a sociolinguistic analysis. En J. L. Green y H, Harker (Eds.), Multiple perppectives analysis of classroom discourse. Norwood, New Jersey: Ablex, pp. 11-47.

Griffin, P. Y Cole, M. (1984). Current activity for the future: The Zo-ped. En B. Rogoff y J. V. Wertsch (Eds.), Children's learning in the zone of proximal development. New Directions for Child Development, $n .^{\circ} 23,45-64$. San Francisco, California: Jossey-Bass.

Kamil, C. (1985). El niño reinventa la aritmética. Madrid: Aprendizaje/Visor.

Leontiev, A. N. (1981). The problem of activity in psychology. En J. V. Wertsch (Ed.), The concept of activity in soviet psychology. Armonk, New York: Sharpe.

Lyons. J. (1983). Lenguaje, significado y contexto. Barcelona: Paidós (Publicación original en inglés en 1981).

Nelson. K. (1988). El descubrimiento del sentido. La adquisición del significado compartido. Madrid: Alianza (Publicación original en inglés en 1986).

PLA, L. (1989). Enseñar y aprender inglés. Bases psicopedagógicas. Barcelona: ICE/Horsori.

Ramirez, A. (1988). Analyzing speech acts. En J. L. Green y J. Harker (Eds.), Multiple perspectives analysis of classroom discourse. Norwood, New Jersey: Ablex, pp. 135-163.

Rogoff, B. (1984). Adult assistance of children's learning. En T. E. Raphael (Ed.), The context of school-based literacy. New York: Random House.

Rocoff, B. (1990). Apprenticeship in thinking. Oxford: Oxford University Press.

Rossell, M. (1980). Epistemología i educació: descripció $i$ anàlisi d'una experiència d'innovació al parvulari. Tesis de Licenciatura no publicada. Facultad de Filosofía y Ciencias de la Educación. Sección de Psicología. Universidad de Barcelona.

Stodolsky, S. (1991). La importancia del contenido en la enseñanza. Actividades en las clases de matemáticas y ciencias sociales. Barcelona: Paidós/M.E.C. (Publicación original en inglés en 1988).

WERTSCH, J. V. (1979). From social interaction to higher psychological processes: as clarification and application of Vygotsky's theory. Human Development, 22, 1-22.

Wertsch, J. V. (1984). The zone of proximal development: some conceptual issues. En B. Rogoff y J. V. Wertsch (Eds.), Children's learning in the zone of proximal development. New Directions for Child Development, $\mathrm{n}^{\circ}$ 23, 7-18. San Francisco. California: Jossey-Bass.

WertsCh, J. V. (1988). Vygotsky y la formación social de la mente. Barcelona: Paidós (Publicación original en inglés en 1985).

WOOD, D. J. (1980). Teaching the young children: some relationships between social interaction, language and thought. En D. R. Olson (Ed.), The social foundations of language and thought. New York: Norton.

Wood, D. J.; Bruner, J. S., Y Ross, G. (1976). The role of tutoring in problem solving. Journal of Child Psychology and Psychiatry, 17, 89-100.

Wood, D. J; WOOK, H. A. Y Middlenton, D. J. (1978). An experimental evaluation of four face-to-face teaching strategies. International Joumal of Bebavioral Development, 1, 131-147.

\section{Extended Summary}

This paper presents the main theoretical and methodological options of a research project made up of several ongoing empirical studies in the Department of Developmental and Educational Psychology at the University of Barcelona. The principal objective of the project is to study some mechanisms of educational influence involved in teacher/pupils's group interaction and adult/child interaction.

Taking the constructivist conception of teaching and learning as a starting point, some basic principles an guiding hypothesis about the study of mechanisms of educational influence are stated. The central idea is that the study of mechanisms of educational influence, involved in teacher/pupils group interaction and adult/child interaction, must be focused on the analysis of interactivity or organizational forms of joint activity; that is to say, on the analysis of the organization of the actions of on participants around the learning content or the performance of the task they are undertaking. Likewise, as a consequence of some critical considerations about the results of previous empirical work, two demands are for the analysis established: first, to respect the time dimension; and secondly, to integrate the specific characteristics of the content and task involved. All this leads to propose the Didactic Sequence (DS) - or, if this is not the case, the Joint Activity Sequence (JAS) - 
as the basic unit for observation, analysis, and interpretation, and to include in the design of the different empirical studies the register of Didactic Sequences with clearly contrasted contents and tasks. Interactivity, that is to say, the forms of organization of joint activity, is seen as the result of a constructive process simultaneously involving teacher and pupils - or adult and child - in which the interrelationship between what they say and do plays an essential role. The participants' speech activity, as a part of the more global context of joint activity, becomes the fundamental object for inquiry and analysis.

The guiding hypothesis and the questions which emerge from this theoretical approach steer the analysis of the forms of organization of joint activity to the inquiry, in the observed and registered Didactic Sequences, of empirical indicators which could be interpreted in terms of progressive transfer of control and responsibility, and of progressive construction of systems of shared meanings. These two processes - transfer of control and construction of systems of shared meanings- are stated as two important mechanisms of educational influence.

The empirical procedure shared by all the empirical studies included in the project implies the observation, register, and analysis of complete Didactical Sequences - or complete Joint Activity Sequences - which respect, as much as possible, the natural context in which they usually appear. Three empirical studies are presented so that the aforementioned procedure can be illustrated.

In order to undertake an exploration of the data according to the demands of the theoretical framework, the establishment of a specific model of analysis has been necessary. This model states different hierarchical units of analysis -Didactical Sequences or Joint Activity Sequences, Sessions, Interactivity Segments, Configurations of Interactivity Segments, Messages, and Configurations of Messages-and two levels of analysis. The first level, more global, takes the Interactivity Segment as the basic unit of analysis, focuses on the evolution of the actions of participants in the ongoing DS or JAS, and pursues the objective of giving some information about the progressive transfer of control and responsibility. The second level, more finegrained, takes the Message as the basic unit of analysis, focuses on the meanings which appear in the speech of participants and which can eventually be negotiated and modified, and pursues the objective of giving some information about how and when the construction of systems of shared meanings takes place. The two levels of analysis are complementary and their respective results mutually support and enrich each other in the perspective of an integrated interpretation. Some examples extracted from the three above mentioned empirical studies are reported for illustrating and exemplifying the units and levels of analysis.

The paper concludes with a critical evaluation of the contributions and limits of the theoretical and methodological approach undertaken in the project, and by underlining several aspects which need further development. Lastly, the analysis of interactivity is placed in the wider context of a more global approach to the study of educational practice. 